\title{
Revista de la
}

\section{CEPAL}

Secretario Ejecutivo

Gert Rosenthal

Secretario Ejecutivo Adjunto

Andrés Bianchi

\section{Director de la Rerista}

Anibal Pinto

Secretario Técrico

Eugenio Lahera

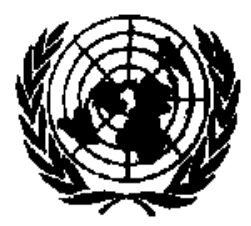

NACIONES UNIDAS

COMISION ECONOMICA PARA AMERICA LATINA Y EL CARIBE

SANTIAGO DE CHILE, DICIEMBRE 1988 


\section{Revista de la}

\section{CEPAL}

\section{SUMARIO}

Competitividad internacional: evolución y lecciones. F. Fajnzylber

Revolución industrial y alternativas regionales. H. Nochteff

Cambio técnico y reestructuración productiva. $E$. Lahera

Notas sobre la automatización microelectrónica en el Brasil. J.R. Tauile

Exportaciones e industrialización en la Argentina, 1973-1986. D. Azprazu y B. Kosacoff

Politica social rural en una estrategia de desarrollo sostenido. $J$. Durston

Interacción de los sectores público y privado y la eficiencia global de la economía. J.M.F. Martin

El problema de la deuda de Cuba en monedas convertibles. A.R.M. Ritter

La seguridad alimentaria; tendencias e impacto de la crisis. A. Schejtman

Economias de viabilidad difícil; una opción por examinar. A. Núñez del Prado

La génesis de la sustitución de importaciones en América Latina. R.L. Ground 
REVISTA DE LA CEPAL $\mathbf{N}^{\circ} 36$

\section{La génesis de la sustitución de importaciones en América Latina}

\author{
Richard Lynn Ground*
}

El proceso de sustitución de importaciones que se pone en marcha en América Latina tras la Gran Depresión fue principalmente una respuesta espontánea al deterioro radical de los precios internacionales de los productos primarios, al fracaso del sistema de comer. cio internacional multilateral (y el colapso del comercio mundial) y al cambio abrupto de dirección de las transferencias de recursos.

La recuperación en las principales economias latinoamericanas fue más acelerada y vigorosa que en la mayorla de los países desarrollados o en la mayoria de las demás regiones en desarrollo. Diffcilmente podría ser más marcado el contraste con los resultados observados como consecuencia del ajuste a la crisis de la deuda internacional en el decenio de 1980.

En la primera y segunda parte del estudio se documenta brevemente la magnitud de los trastornos de origen externo, se examina la respuesta de las políticas internas y se presenta una visión general de la evolu. ción del crecimiento de las economias latinoamericanas durante la Gran Depresión y la Segunda Guerra Mundial. En la tercera parte, se analizan las ideas de Prebisch y, además, el origen de las distorsiones de precios en América Latina.

*El autor fue anteriormente funcionario de la Divişión de Desarrollo Economico de la CEPAL y en la actualidad se desempeôa en el Barico Mundial. Desea dejar constancia de sus agradecimientos a Andrés Bjanchi y Anfbal Pinto, por sus comentarios y su estimulo. Las opiniones expresadas en el artículo son del autor y no conprometen a la CrPaL nial Banco Mundial. El autor se hace responsable de los errores o deficiencias que pueda presentar el trabajo.

E] presente articulo es una versión levemente modificada de un capítulo del ensayo titulado "The economic develop" mest of Latin America. Towands a concribution to a new synthesis of development theor $y^{\prime \prime}$, cuyos autores bon Richard L. Ground y Andres Bianchi. Dicho ensayo fue presentado en un seminario titulado "A Comparative Study of Economic Development in Asia and Latin America", realizado en Tokio entre el 22 y el 24 de febrero de 1988 , que fue auspiciado por el Institute of Developing Eorminies.

\section{La Gran Depresión y la génesis de la sustitución de importaciones}

La relación de precios del intercambio de la mayoria de los países latinoamericanos disminuyo de manera continua durante el decenio de 1920, a raíz de la deflación gradual del nivel mundial de precios y la acumulación de existencias masivas de productos primarios tras el alza espectacular de los precios internacionales, especialmente los de los productos básicos, en los últimos años de la Primera Guerra Mundial. A pesar de ello, los años veinte constituyeron en general un decenio de elevado crecimiento en América Latina, ya que la demanda mundial mantuvo su dinamismo y se produjo una afluencia sin precedentes de capital hacia la región. Así, a pesar de que el precio internacional medio de los productos primarios más transados cayó alrededor de $40 \%$ entre los primeros y los últimos años del decenio de $1920^{\circ}$, paises como Argentina y Colombia registraron tasas globales de crecimiento de casi $6 \%$ y más del $7 \%$, respectivamente, en el transcurso de ese decenio; en el periodo 1925-1929, Chile alcanzó una tasa de crecimiento de casi $11 \%$; Colombia y Brasil registraron expansiones superiores al $7 \%$, y Argentina y Honduras crecimientos cercanos al $6 \%$ (cuadro 1) ${ }^{2}$.

\section{El alcance y la transmisión de la depresión de los patses industriales}

Entre 1929 y 1933 el índice del producto interno bruto del conjunto de los países industrializados cayó $17 \%^{3}$. En los Estados Unidos, que tras la

\footnotetext{
'Véase D. Félix, "Alternative outcomes of the Latin American debt crisis: lessons from the past", Latin American Research Review, vol. 22, No 2 (1987), cuadro 3. Nótese que entre 1923 y 1929 las existencias mundiales de los principales productos básicos internacionales se duplicaron con creces.

2Véase también CEPAL, Series históricas del crecimiento de América Latina, Serie Cuadernos Estadísticos de la CEPAL, $N^{\circ}$ 3, Santiago de Chile, 1978.

${ }^{3}$ A. Maddison, 1985, 13, citado en D. Eichengreen y $R$. Portes, "The anatomy of financial crisis", Seminar Paper $N^{a} 375$, Institute for International Economic Studies (Universidad de Estocolmo), enero de 1987.
} 
Cuadro 1

AMERICA LATINA: EVOLUCION DEL PRODUCTO INTERNO BRUTO

EN ALGUNOS PAISES, 1920-1950*

(Tases de crecimiento medio anual)

\begin{tabular}{|c|c|c|c|c|}
\hline Pais & $1920-1929$ & $1929-1939$ & $1939-1945$ & $1945-1950$ \\
\hline América Latina & $\cdots$ & $\cdots$ & 3.4 & 5.3 \\
\hline Argentina & 5.7 & 1.6 & 2.1 & 3.9 \\
\hline Brasil & 3.3 & 3.0 & 2.4 & 6.1 \\
\hline Colombia $^{\mathrm{h}}$ & 7.3 & 3.8 & 2.6 & 4.7 \\
\hline Costa Rica' & $\ldots$ & $\ldots$ & $\ldots$ & 6.4 \\
\hline Chile $^{d}$ & $\cdots$ & $\ldots$ & 4.0 & 2.9 \\
\hline Ecuador & $\ldots$ & $\ldots$ & 4.2 & 9.4 \\
\hline El Salvador & $\cdots$ & $\ldots$ & $\cdots$ & 8.8 \\
\hline Guatemala $^{c}$ & $\cdots$ & $\cdots$ & $\cdots$ & 0.8 \\
\hline Haiti & $\ldots$ & $\ldots$ & $\cdots$ & 1.2 \\
\hline Honduras $^{b}$ & 5.4 & $-\mathbf{I} .1$ & 3.5 & 4.1 \\
\hline México ${ }^{e}$ & 1.7 & 2.1 & 6.2 & 6.3 \\
\hline Nicaragua & $\cdots$ & $\cdots$ & $\ldots$ & 6.3 \\
\hline Panamá & $\cdots$ & $\ldots$ & $\ldots$ & 0.5 \\
\hline Paraguay & $\cdots$ & $\cdots$ & 0.4 & 2.1 \\
\hline Perú & $\cdots$ & $\cdots$ & $\ldots$ & 4.5 \\
\hline República Dominicana & $\ldots$ & $\cdots$ & $\ldots$ & 8.4 \\
\hline Uruguay & $\cdots$ & $\cdots$ & 1.7 & 5.4 \\
\hline Venezuela & $\cdots$ & $\ldots$ & 5.3 & 10.6 \\
\hline
\end{tabular}

Fuente: CEPAL, a base de informaciones oficiales.

- Precios de 1970.

b 1925-1929.

c 1946-1950.

d 1940-1945.

e 1921.1929.

Primera Guerra Mundial habia llegado a tener un lugar preeminente en el comercio latinoamericano, la depresión fue especialmente grave. En efecto, entre 1929 y 1933 el producto disminuyó abruptamente en más de $29 \%$. Entre los demás paises con importante participación comercial en la región, la contracción de la actividad económica llegó a 30\% en el Canadá, $16 \%$ en Alemania y $11 \%$ en Francia, considerando sus respectivos puntos máximos y mínimos de actividad económica antes de la depresión y durante ésta. Sólo en el Reino Unido, cuyo comercio con países como Argentina y Uruguay era decisivo, la baja tuvo rasgos más propios de una recesión, ya que el producto en ese país se redujo sólo $5 \%$ entre 1929 y $1931^{4}$.

A raíz de esta involución de la actividad eco-

${ }^{4}$ A. Maddison, Phases of Capitalist Dezelopment (Oxford: Oxford University Press, 1982), cuadro A6. nómica, y junto con ella, el desempleo alcanzó niveles sin precedentes. Es más, en Estados Unidos la tasa de desempleo de la fuerza de trabajo subió vertiginosamente de $3 \%$ en 1929 a más de 22\% en 1932; en Canadá, aumentó desde menos de $2 \%$ en 1928 a más de $19 \%$ en 1932; en Alema. nia se cuadrupticó con creces, de $3.8 \%$ a $17.2 \%$ en el mismo perfodo, y en Gran Bretaña creció de alrededor de $7 \%$ a más de $15 \%$ entre 1929 y $1932^{5}$.

La deflación de precios en Norteamérica fue en general paralela a la reducción de la actividad económica, mientras en los otros grandes paises industrializados sobrepaso de manera considerable la contracción del producto. Así, el nivel de precios en los Estados Unidos, tras haber disminuido $15 \%$ durante el decenio de 1920 , cayó $25 \%$ entre 1929 y 1933, y en Canadá bajó casi $30 \%$ en

${ }^{5}$ Ibid., cuadro $\mathbf{C 6}$. 
los primeros años de la depresión. Por otra parte, la reducción media de los precios en Francia, es decir, $30 \%$, casi triplicó la del producto interno bruto; en Alemania duplicó con creces la caída de dicho producto, y en Gran Bretaña duplicó igualmente la reducción de la actividad económi$\mathrm{ca}$, pero fue en consecuencia considerablemente menos pronunciada que en los demás paises desarrollados ${ }^{6}$.

Por todo ello, la disminución de la demanda de dinero en los países industrializados, y por lo tanto del valor nominal del comercio mundial, superó con mucho la contracción de la actividad económica en estos países y la reducción del volumen de las importaciones mundiales. En efecto, el índice del volumen de importaciones del conjunto de los paises industrializados bajo 23.5\% entre 1929 y 1932 , pero el valor nominal de las importaciones de dichos países cayó $49 \%^{7}$.

Además, la disminución de los precios internacionales de los productos primarios fue considerablemente mayor que la de la media de los precios internacionales, y por lo tanto excedió ostensiblemente la deflación de los precios internacionales de los bienes manufacturados y los servicios. Así, la relación de precios del intercambio del conjunto de los países desarrollados de hecho mejor 6 casi $15 \%$ entre su nivel máximo de actividad económica, registrado en 1929 , y los niveles mínimos de ésta, durante la Gran Depresión en $1935^{\circ}$.

La desintegración que se observó en el comercio mundial de mercancías, tuvo también su base en el violento cambio de dirección de las transferencias de recursos. En efecto, mientras la inversión neta de los Estados Unidos y el Reino Unido en el exterior ascendió a más de 11300 millones de dólares entre mediados y fines del decenio de 1920, entre 1930 y 1934 los países industrializados repatriaron 8400 millones de dólares de capital desde el resto del mundo, y en el período 1935-1938 otros 4800 millones de dólares ${ }^{9}$. La transferencia total de recursos desde las naciones deudoras a las acreedoras durante este periodo fue considerablemente más grande,

\footnotetext{
${ }^{6}$ lbid., cuadro C3.

${ }^{7}$ Calculado a partir de datos en $B$. Eichengreen y $R$. Portes, op. cit., 1987, cuadro 3.

9loid.

Ibid., p. 16 y 19.
}

especialmente durante los primeros años del decenio de 1930 , cuando un buen número de naciones deudoras continuó pagando al menos parcialmente los intereses de sus deudas externas. Las remesas de utilidades se mantuvieron, en una escala muy reducida, durante todo el periodo. De este modo, el ingreso interno, y especialmente la absorción interna, disminuyeron significativamente menos que el producto en los paises desarrollados.

La contracción del volumen y particularmente el valor de las importaciones de los paises industrializados excedió en mucho el alcance de la declinación de la actividad económica de esos países. Esto se debió, desde luego, a gigantescas barreras comerciales y al otorgamiento de subsidios masivos a la producción ${ }^{10}$. Si en lugar de adoptar estas políticas se hubiera recurrido principalmente a los tipos de cambio para ajustar los precios relativos, el alcance y la duración de la caída de la actividad económica, especialmente del comercio mundial, habrían sido notoriamente inferiores, a pesar de las políticas monetarias y fiscales decididamente procíclicas que la mayoría de esos países aplicó hasta vísperas de la Segunda Guerra Mundial $^{11}$. El curso de la historia de la economía mundial, y tal vez especialmente de la historia económica latinoamericana, habria sido muy diferente en ese caso. i

\section{Magnitud de los trastornos externos}

Las perturbaciones económicas que se transmitieron al resto del mundo aumentaton de este modo en gran medida los efectos de la Gran Depresión en los propios países industriales. Además, los efectos de esas perturbaciones externas en las economías latinoamericanas fueron especialmente grandes, debido principalmente a

\footnotetext{
${ }^{10}$ Para una resejia de las radicales restricciones comerciales cuantitativas impuestas por los paises desarrollados en este periodo véase, por ejemplo, A.G. Kenwood y A.L. Loughedd, The Growth of the International Econony 1820.1980, Londres, George Allen and Unwin, 1983. Notese que entre 1928 y 1931 la existencia mundial de los productos primarios más comerciados se expandió casi $90 \%$ (Félix, op. cit., 1987, cuadro 3).

"Véase el análisis presentado en B. Ejchengreen y J. Sachs, "Exchange rates and economic recovery in the 1980s". The Journal of Economic History, vol. xıv, diciembre de 1985; pp. 925 a 946 .
} 
la influencia preponderante de la economía de los Estados Únidos en la región.

Aunque para la región en su conjunto la disminución del volumen de exportaciones no fue mucho mayor que la de los paises industrializados $(27 \% \text { contra } 23.5 \%)^{12}$, el colapso del valor nominal de las exportaciones de América Latina no guardó proporción alguna con la cafda del valor nominal de las importaciones de los países industriales ni con la deflación del valor monetario del producto interno bruto de éstos. Asl, por ejemplo, el valor corriente de las exportaciones de Chile cayó $88 \%$ entre 1929 y 1933; el de El Salvador, $78 \%$ entre 1928 y 1932; los de México, Venezuela, Perú y Argentina, entre $75 \%$ y alrededor de $70 \%$; el de Colombia, $67 \%$ y el del Brasil, $63 \%{ }^{13}$. A modo de contraste, el valor monetario de las importaciones de los países industrializados disminuyó algo menos de 50\%.

Y si bien por supuesto los precios de las importaciones de la región también se redujeron, la baja fue considerablemente menor que la caída en picada de los precios de sus exportaciones. En efecto, para la región en su conjunto la relación de precios del intercambio se desplomó casi $48 \%$ entre 1928 y 1932 (cuadro 2). La de Venezuela se deterioró no menos de $65 \%$ entre 1930 y 1935 ; la de El Salvador, $53 \%$, y la del Brasil, algo menos de 50\%. En Chile, Colombia, Perú y México, la relación disminuyó entre $45 \%$ y $40 \%$ desde el punto máximo (registrado en 1928 o poco después) hasta el punto mínimo de actividad económica (registrado hasta 1934); las reducciones experimentadas por el Ecuador y la Argentina fueron algo menores, es decir, $38 \%$ y $35 \%$, respectivamente ${ }^{14}$.

En agudo contraste con el resultado para los países industrializados, el poder de compra de las exportaciones de América Latina se contrajo mucho más marcadamente que su volumen de ex-

\footnotetext{
${ }^{12}$ B. Eichengreen y R. Portes, op, cil., 1987, cuadros 3 y 4. Sin embargo, en unos pocos casos el alcance de la contracción del volumen de exportaciones llego a proporciones catastróficas; un ejemplo es Méxica, donde cayo más de $41 \%$, y otro aún más notable, Chile, donde efectivamente descendió más de $71 \%$ (véase el cuadro 6 ).

${ }^{13}$ CEPAL, America Latina: relación de precios del intercambio, serie Cuadernos Estadísticos de la C.EpaL, $\mathrm{N}^{0} 1$, Santiago de Chile, 1976, cuadros por páses.

${ }^{14} \mathrm{Ibid}$.
}

portaciones. En el plano regional, el valor real de las exportaciones cayo $48 \%$ entre 1929 y 1933, o casi el doble de la disminución de su volumen de exportaciones. En este mismo período, el valor real de las exportaciones de los paises desarrollados disminuyó $13 \%$, es decir, menos de la mitad de lo que se redujo su volumen total de exportaciones $^{15}$.

Si la proporción entre el valor de las exportaciones y el producto interno bruto de América Latina hubiese sido del orden del $40 \%$ en 1929 , la pérdida directa debida al deterioro radical de su relación de precios del intercambio habría excedido la cifra de $12 \%$ en 1933 únicamente, mientras que la caída total del ingreso interno en 1933 en comparación con 1929, como consecuencia de la involución del valor real de sus exportaciones, se habría aproximado al $21 \%$. Si la contribución de las exportaciones al ingreso interno bruto hubiese sido del orden del $10 \%$ en los paises desarrollados en 1929 , sus pérdidas correspondientes habrían sido $1.5 \%$ y $2.4 \%$, respectivamente.

Sin embargo, la magnitud de la depresion del volumen de las importaciones de América Latina fue incluso mayor que la compresión del poder de compra de sus exportaciones. En efecto, entre 1929 y 1933 el volumen de las importaciones de la región disminuyó más de $60 \%$ (cuadro 3). Este ajuste adicional fue provocado por el violento cambio de dirección de las transferencias de recursos. Como resultado de la repatriación masiva de capital extranjero y el alza vertiginosa del tipo de interés internacional real ex post como consecuencia de la deflación sostenida del nivel mundial de precios ${ }^{16}$, la absorción interna

${ }^{15}$ B. Eichengreen y R. Portes, op. cit., 1987, cuadros 3 y 4.

${ }^{16}$ Entte 1929 y 1930 el tipo de interés real ex post tes decir, el tipo de interés nominal de los Estados Unidos deflactado por el cambio en el valor unitario de las exportaciones estadounidenses) subió de alrededor de $3 \%$ a cerca de $16 \%$ y se elevó vertiginosamente a $33 \%$ en 1931 , antes de descender a alrededor de $18 \%$ en 1982 y volverse negativo en 1933 , cuando comenzó la deflación. Sin embargo, si nos concentramos en el tipo de interés internacional real ex post a que tenia que hacer frente América Latina (es decir, el tipo de interés nominal de los Estados Unidos deflactado por el cambio en el precio medio de las exportaciones de América Latina), el salto fue mucho más impresionante todavia. En efecto, subió desde más de $14 \%$ en 1929 a $50 \%$ en $1930, y$ a casi $52 \%$ en 1931 . antes de disminuir a alrededor de $19 \%$ en 1932 . En 1933 se alzó a $27 \%$, pero cayó a $6 \%$ en 1934 y se tornó negativo en 
Cuadro 2

AMERICA LATINA: EVOLUCION DE LA RELACION DE PRECIOS DEL INTERCAMBIO DE MERCANCIAS

\begin{tabular}{|c|c|c|c|c|c|c|}
\hline$A \bar{n} 0$ & $\begin{array}{l}\text { Indice de } \\
\text { precios de } \\
\text { exportacion }\end{array}$ & $\begin{array}{l}\text { Indice de } \\
\text { precios de } \\
\text { importación }\end{array}$ & $\begin{array}{l}\text { Relación de } \\
\text { precios del } \\
\text { intercambio } \\
\text { de mercancfas }\end{array}$ & $\begin{array}{l}\text { Volumen de } \\
\text { exportaciones }\end{array}$ & $\begin{array}{c}\text { Poder de compra } \\
\text { de las } \\
\text { exportaciones }\end{array}$ & $\begin{array}{l}\text { Volumen de } \\
\text { importaciones }\end{array}$ \\
\hline 1928 & 100.0 & 100.0 & 100.0 & 100,0 & 100.0 & 100.0 \\
\hline 1929 & 90.6 & 96.2 & 94.2 & 103.1 & 97.1 & 106.4 \\
\hline 1930 & 62.3 & 93.3 & 66.8 & 87.9 & 58.7 & 75.8 \\
\hline 1931 & 41.8 & 79.2 & 52.8 & 93.0 & 49.1 & 51.9 \\
\hline 1932 & 96.2 & 55.1 & 55.6 & 77.8 & 43.3 & 37.9 \\
\hline 1933 & 29.3 & 56.6 & 51.8 & 81.2 & 42.1 & 46.3 \\
\hline 1984 & 28.4 & 48.1 & 59.0 & 91.3 & 53.9 & 51.9 \\
\hline 1985 & 31.8 & 48.1 & 66.1 & 105.6 & 69.8 & 56.1 \\
\hline 1996 & 33.9 & 48.1 & 70.5 & 109.3 & 77.1 & 60.3 \\
\hline 1987 & 38.1 & 52.9 & 72.8 & 120.4 & 87.7 & 75.7 \\
\hline 1988 & 34.9 & 50.9 & 68.6 & 96.3 & 66.1 & 70.1 \\
\hline 1939 & 33.8 & 49.5 & 68.3 & 101.8 & 69.5 & 68.7 \\
\hline 1940 & 35.9 & 58.3 & 67.4 & 90.7 & 61.1 & 58.9 \\
\hline 1941 & 40.1 & 57.6 & 69.6 & 94.4 & 69.9 & 60.3 \\
\hline 1942 & 44.8 & 67.7 & 66.2 & 88.2 & 58.4 & 46.3 \\
\hline 1943 & 49.7 & 73.5 & 67.6 & 96.0 & 64.9 & 47.7 \\
\hline 1944 & 53.6 & 73.5 & 78.0 & 101.9 & 74.4 & 58.9 \\
\hline 1945 & 54.6 & 79.2 & 68.9 & 111.3 & 76.7 & 65.9 \\
\hline 1946 & 71.2 & 92.2 & 77.2 & 119.1 & 91.9 & 86.9 \\
\hline 1947 & 89.7 & 115.9 & 77.8 & 121.1 & 89.7 & 119.1 \\
\hline 1948 & 99.4 & 129.9 & 80.2 & 121.1 & 94.2 & 116.3 \\
\hline 1949 & 93.6 & 129.9 & 75.5 & 111.3 & 84.0 & 108.7 \\
\hline 1950 & 110.5 & 118.1 & 98.6 & 115.2 & 107.8 & 105.1 \\
\hline 1951 & 190.4 & 141.2 & 92.4 & 115.2 & 106.4 & 130.3 \\
\hline 1952 & 93.9 & 144.1 & 65.2 & 111.9 & 72.6 & 124.7 \\
\hline 1953 & 93.9 & 184.0 & 70.1 & 1280 & 86.2 & 114.9 \\
\hline 1954 & 97.7 & 196.9 & 71,4 & 123.0 & 87.8 & 128.9 \\
\hline 1955 & 87.3 & 199.8 & 62.4 & 190.8 & 81.6 & 128.9 \\
\hline 1956 & 85.9 & 139.8 & 61.4 & 142.5 & 87.5 & 134.5 \\
\hline 1957 & 88.1 & 141,2 & 62.4 & 146.4 & 91.4 & 155.5 \\
\hline 1958 & 80.9 & 139.8 & 60.0 & 148.4 & 89.0 & 142.9 \\
\hline 1959 & 73.0 & 135.4 & 53.9 & 162.1 & 87.4 & 198.7 \\
\hline 1960 & 74,4 & 138.3 & 53.8 & 166.0 & 89.8 & 142.9 \\
\hline 1961 & 74.4 & 141.2 & 52.7 & 171.9 & 90.6 & 145.7 \\
\hline 1962 & 71.5 & 144.1 & 49.6 & 187.5 & 98.0 & 144.3 \\
\hline 1963 & 72.2 & 144.1 & 50.1 & 195.3 & 97.8 & 140.1 \\
\hline 1964 & 76.5 & 149.9 & 51.1 & 197.3 & 100.8 & 148.5 \\
\hline 1965 & 75.1 & 152.7 & 49.2 & 211.0 & 109.8 & 149.9 \\
\hline 1966 & 76.5 & 152.7 & 50]$. & 218.8 & 109.6 & 166.9 \\
\hline 1967 & 75.8 & 154.1 & 49.2 & 220.8 & 108.6 & 174.0 \\
\hline 1968 & 76.2 & 152.7 & 49.9 & 230.6 & 115.1 & 191.0 \\
\hline 1969 & 78.4 & 155.6 & 50.4 & 246.2 & 124.1 & 206.6 \\
\hline 1970 & 84.1 & 159.9 & 52.6 & 254,0 & 133.6 & 299.2 \\
\hline 1971 & 79.8 & 164.9 & 48.3 & 275.8 & 139.2 & 146.7 \\
\hline 1972 & 110.8 & 178,1 & 62.1 & 251.7 & 158.2 & 260.2 \\
\hline 1973 & 129.9 & 204.2 & 63.6 & 304.0 & 193.9 & 301.4 \\
\hline 1974 & 216.5 & 293.8 & 73.6 & 264.0 & 194.3 & 359.0 \\
\hline 1975 & 218.6 & 325.9 & 67.2 & 240.5 & 161.6 & 345.2 \\
\hline 1976 & 234.7 & $\mathbf{9 3 t . 5}$ & 70.8 & 260.9 & 184.7 & $351, B$ \\
\hline 1977 & 269.9 & $\$ 58.0$ & 75.4 & 271.0 & 204.3 & 374.9 \\
\hline 1978 & 278.9 & $\$ 92.9$ & 70.9 & 281.9 & 199.9 & 388.5 \\
\hline 1979 & 340,8 & 458.7 & 74.2 & 310.1 & 230.1 & 418.2 \\
\hline 1980 & 424.4 & 553.4 & 76.7 & $\$ 29.4$ & 252.6 & 501.2 \\
\hline I981 & 418.9 & 581.6 & 72.0 & 358.9 & 258.4 & 515.6 \\
\hline 1982 & $\mathbf{3 7 9 . 0}$ & 544.4 & 65.9 & 362.0 & 238.6 & 418.3 \\
\hline 1983 & 341.7 & 522.9 & 65.3 & 401.8 & 262.4 & 328.9 \\
\hline 1984 & 354.3 & 501.8 & 70.6 & 432.3 & 305.2 & 356.0 \\
\hline 1985 & 397.4 & 493.5 & 68.8 & 427.0 & 291.6 & $\mathbf{9 6 9 . 4}$ \\
\hline 1986 & 291.5 & 469.8 & 62.1 & 417.8 & 259.5 & 389.0 \\
\hline 1987 & 311.6 & 487.6 & 65.6 & 498.4 & 278.8 & 410.8 \\
\hline
\end{tabular}

Fuente: Para el perfodo 1928-1970, GEPAL; para el perfodo 197I-1987, Banco de Datos de la CEPAL. 
Cuadro 3

AMERICA LATINA: EVOLUCION DEL, VOLUMEN DE EXPORTACIONES E IMPORTACIONES DE BIENES EN ALGUNOS PAISES, 1928.1950 $(1963=100)$

\begin{tabular}{|c|c|c|c|c|c|c|c|c|c|c|}
\hline \multirow{2}{*}{ Año } & \multicolumn{2}{|c|}{ Argentina } & \multicolumn{2}{|c|}{ Bolivia } & \multicolumn{2}{|c|}{ Brasil } & \multicolumn{2}{|c|}{ Colombia } & \multicolumn{2}{|c|}{ Costa Rica } \\
\hline & $\begin{array}{l}\text { Exporta } \\
\text { ciones }\end{array}$ & $\begin{array}{l}\text { Importa- } \\
\text { ciones }\end{array}$ & $\begin{array}{c}\text { Exporta- } \\
\text { ciones }\end{array}$ & $\begin{array}{c}\text { Importa- } \\
\text { ciones }\end{array}$ & $\begin{array}{l}\text { Exporta- } \\
\text { ciones }\end{array}$ & $\begin{array}{l}\text { Importa- } \\
\text { ciones }\end{array}$ & $\begin{array}{c}\text { Exporta- } \\
\text { ciones }\end{array}$ & $\begin{array}{c}\text { Importa- } \\
\text { ciones }\end{array}$ & $\begin{array}{c}\text { Exporta- } \\
\text { ciones }\end{array}$ & $\begin{array}{c}\text { Importa- } \\
\text { ciones }\end{array}$ \\
\hline 1928 & 126 & 150 & $\cdots$ & $\cdots$ & 49 & 68 & 49 & 76 & $\ldots$ & $\ldots$ \\
\hline 1929 & 127 & 156 & 29 & $\ldots$ & 52 & 69 & 51 & 65 & $\ldots$ & $\cdots$ \\
\hline 1930 & 88 & 137 & 26 & $\ldots$ & 57 & 41 & 56 & 34 & $\cdots$ & $\cdots$ \\
\hline 1931 & 121 & 96 & 20 & $\cdots$ & 6] & 27 & 49 & 29 & $\ldots$ & $\ldots$ \\
\hline 1932 & 111 & 73 & 23 & $\cdots$ & 42 & 25 & 50 & 24 & $\cdots$ & $\cdots$ \\
\hline I933 & 104 & 80 & 43 & $\cdots$ & 52 & 35 & 50 & 33 & $\cdots$ & $\cdots$ \\
\hline 1934 & 109 & 88 & 56 & $\cdots$ & 58 & 38 & 53 & 41 & $\cdots$ & $\cdots$ \\
\hline 1935 & 115 & 91 & 50 & $\cdots$ & 67 & 43 & 58 & 45 & $\cdots$ & $\cdots$ \\
\hline 1936 & 104 & 96 & 37 & $\cdots$ & 74 & 44 & 65 & 51 & $\cdots$ & $\cdots$ \\
\hline 1937 & 121 & 126 & 43 & 46 & 67 & 54 & 64 & 59 & 51 & 25 \\
\hline 1938 & 78 & 119 & 33 & 57 & 81 & 50 & 67 & 55 & 47 & 28 \\
\hline 1939 & 100 & 100 & 38 & 54 & 83 & 46 & 65 & 67 & 42 & 36 \\
\hline 1940 & 85 & 86 & 45 & 53 & 69 & 41 & 69 & 47 & 35 & 31 \\
\hline 1941 & 76 & 68 & 49 & 71 & 75 & 41 & 53 & 49 & 43 & 30 \\
\hline 1942 & 74 & 56 & 56 & 68 & 57 & 30 & 58 & 26 & 39 & 20 \\
\hline 1943 & 76 & 37 & 65 & 73 & 58 & 39 & 74 & 31 & 42 & 26 \\
\hline 1944 & 83 & 37 & 65 & 71 & 68 & 48 & 48 & 37 & 35 & 28 \\
\hline 1945 & 85 & 41 & 65 & 61 & 74 & 47 & 79 & 59 & 37 & 31 \\
\hline 1946 & 88 & 81 & 67 & 68 & 91 & 60 & 82 & 73 & 36 & 36 \\
\hline 1947 & 96 & 147 & 82 & 68 & 86 & 86 & 79 & 99 & 48 & 44 \\
\hline 1948 & 87 & 164 & 89 & 72 & 90 & 77 & 80 & 80 & 62 & 34 \\
\hline 1949 & 58 & 112 & 86 & 79 & 87 & 75 & 80 & 64 & 58 & 37 \\
\hline 1950 & 72 & 101 & 84 & 54 & 70 & 85 & 70 & 86 & 55 & 42 \\
\hline
\end{tabular}

\begin{tabular}{|c|c|c|c|c|c|c|c|c|}
\hline \multirow{2}{*}{ Año } & \multicolumn{2}{|c|}{ Chile } & \multicolumn{2}{|c|}{ Ecuador } & \multicolumn{2}{|c|}{ El Salvador } & \multicolumn{2}{|c|}{ Guatemala } \\
\hline & $\begin{array}{l}\text { Exporta- } \\
\text { ciones }\end{array}$ & $\begin{array}{l}\text { Importa- } \\
\text { ciones }\end{array}$ & $\begin{array}{l}\text { Exporta- } \\
\text { ciones }\end{array}$ & $\begin{array}{l}\text { Importa- } \\
\text { ciones }\end{array}$ & $\begin{array}{c}\text { Exporta- } \\
\text { ciones }\end{array}$ & $\begin{array}{l}\text { Importa- } \\
\text { ciones }\end{array}$ & $\begin{array}{c}\text { Exporta- } \\
\text { ciones }\end{array}$ & $\begin{array}{c}\text { Importa- } \\
\text { ciones }\end{array}$ \\
\hline 1928 & 75 & 79 & 23 & 29 & 28 & 26 &.. & $\cdots$ \\
\hline 1929 & 80 & 100 & 23 & 29 & 25 & 29 & $\cdots$ & $\ldots$ \\
\hline 1930 & 52 & 92 & 24 & 23 & 31 & 16 & $\cdots$ & $\ldots$ \\
\hline 1931 & 48 & 48 & 18 & 16 & 30 & 13 & $\cdots$ & $\ldots$ \\
\hline 1932 & 23 & 17 & 19 & 12 & 21 & 12 & ..' & $\cdots$ \\
\hline 1933 & 33 & 19 & 17 & 13 & 30 & 14 & $\ldots$ & $\ldots$ \\
\hline 1934 & 53 & 25 & 26 & 18 & 25 & 18 & $\ldots$ & $\cdots$ \\
\hline 1935 & 54 & 38 & 28 & 23 & 24 & 15 & $\cdots$ & $\ldots$ \\
\hline 1936 & 54 & 43 & 25 & 25 & 28 & 15 & $\cdots$ & $\cdots$ \\
\hline 1937 & 76 & 48 & 26 & 21 & 37 & 17 & 41 & 32 \\
\hline 1938 & 71 & 44 & 25 & 23 & 28 & 14 & 43 & 30 \\
\hline 1939 & 64 & 56 & 25 & 29 & 39 & 16 & 41 & 30 \\
\hline 1940 & 70 & 42 & 25 & 23 & 15 & 14 & 37 & 24 \\
\hline 1941 & 77 & 49 & 24 & 19 & 24 & 16 & 37 & 23 \\
\hline 1942 & 82 & 41 & 27 & 22 & 30 & 15 & 42 & 18 \\
\hline 1943 & 75 & 42 & 34 & 20 & 33 & L6 & 41 & 19 \\
\hline 1944 & 78 & 42 & 34 & 27 & 35 & 16 & 41 & 23 \\
\hline 1945 & 79 & 45 & 29 & 27 & 31 & 18 & 51 & 25 \\
\hline 1946 & 72 & 45 & 29 & 36 & 27 & 19 & 47 & 33 \\
\hline 1947 & 72 & 47 & 28 & 42 & 36 & 28 & 56 & 33 \\
\hline 1948 & 79 & 62 & 29 & 45 & 37 & 29 & 51 & 48 \\
\hline 1949 & 71 & 75 & 26 & 48 & 42 & 29 & 45 & 52 \\
\hline 1950 & 69 & 55 & 37 & 46 & 40 & 38 & 44 & 55 \\
\hline
\end{tabular}


Cuadro 3 (conclusión)

\begin{tabular}{|c|c|c|c|c|c|c|c|c|c|c|}
\hline \multirow{2}{*}{ Año } & \multicolumn{2}{|c|}{ Haiti } & \multicolumn{2}{|c|}{ Honduras } & \multicolumn{2}{|c|}{ México } & \multicolumn{2}{|c|}{ Nicaragua } & \multicolumn{2}{|c|}{ Panamá } \\
\hline & $\begin{array}{l}\text { Exporta- } \\
\text { ciones }\end{array}$ & $\begin{array}{l}\text { Importa- } \\
\text { ciones }\end{array}$ & $\begin{array}{l}\text { Exporta- } \\
\text { ciones }\end{array}$ & $\begin{array}{l}\text { Importa- } \\
\text { ciones }\end{array}$ & $\begin{array}{l}\text { Exporta- } \\
\text { ciones }\end{array}$ & $\begin{array}{l}\text { Importa- } \\
\text { ciones }\end{array}$ & $\begin{array}{l}\text { Exporta- } \\
\text { ciones }\end{array}$ & $\begin{array}{l}\text { Importa- } \\
\text { ciones }\end{array}$ & $\begin{array}{c}\text { Exporta- } \\
\text { ciones }\end{array}$ & $\begin{array}{l}\text { Importa- } \\
\text { ciones }\end{array}$ \\
\hline 1928 & $\ldots$ & $\ldots$ & $\cdots$ & $\cdots$ & 106 & 47 & $\cdots$ & $\cdots$ & $\ldots$ & $\ldots$ \\
\hline 1929 & $\ldots$ & $\cdots$ & $\ldots$ & $\ldots$ & 106 & 54 & $\ldots$ & $\ldots$ & $\cdots$ & $\cdots$ \\
\hline 1980 & 45 & $\ldots$ & $\cdots$ & $\ldots$ & 86 & 40 & $\cdots$ & $\cdots$ & $\ldots$ & $\ldots$ \\
\hline 1931 & 45 & $\cdots$ & $\ldots$ & $\ldots$ & 87 & 26 & $\ldots$ & $\ldots$ & $\cdots$ & $\ldots$ \\
\hline 1932 & 47 & $\ldots$ & $\cdots$ & $\cdots$ & 62 & 21 & $\cdots$ & $\cdots$ & $\cdots$ & $\ldots$ \\
\hline 1933 & 70 & $\cdots$ & $\ldots$ & $\ldots$ & 667 & 24 & $\ldots$ & $\ldots$ & $\ldots$ & $\ldots$ \\
\hline 1934 & 64 & $\ldots$ & $\ldots$ & $\ldots$ & 90 & 30 & $\ldots$ & $\cdots$ & $\cdots$ & $\ldots$ \\
\hline 1935 & 49 & $\cdots$ & $\ldots$ & $\cdots$ & 92 & 31 & $\cdots$ & $\ldots$ & $\ldots$ & $\ldots$ \\
\hline 1936 & 70 & $\cdots$ & $\ldots$ & $\ldots$ & 101 & 36 & $\ldots$ & $\ldots$ & $\ldots$ & $\ldots$ \\
\hline I937 & 57 & $\cdots$ & 53 & 30 & 119 & 46 & 24 & 115 & 33 & 42 \\
\hline 1938 & 60 & $\cdots$ & 39 & 28 & 53 & 38 & 19 & 15 & 31 & 96 \\
\hline 1939 & 66 & $\cdots$ & 54 & 90 & 50 & 85 & 20 & 17 & 32 & 41 \\
\hline 1940 & 46 & $\cdots$ & 52 & 29 & 43 & 33 & 16 & 16 & 31 & 39 \\
\hline 1941 & 56 & $\cdots$ & 53 & 29 & 47 & 49 & 14 & 22 & 24 & 52 \\
\hline 1942 & 47 & $\ldots$ & 50 & 18 & 48 & 36 & 14 & 13 & 13 & 46 \\
\hline 1943 & 53 & $\ldots$ & 25 & 23 & 56 & 43 & 17 & 23 & 13 & 43 \\
\hline 1944 & 77 & $\ldots$ & 49 & 25 & 46 & 64 & 18 & 16 & 19 & 37 \\
\hline 1945 & 72 & $\cdots$ & 61 & 30 & 54 & 76 & 15 & 17 & 19 & 43 \\
\hline 1946 & 81 & $\ldots$ & 64 & 40 & $\mathbf{5 5}$ & 102 & 18 & 19 & 28 & 52 \\
\hline 1947 & 77 & $\ldots$ & 79 & 49 & 56 & 109 & 17 & 24 & 34 & 58 \\
\hline 1948 & 73 & $\ldots$ & 89 & 52 & 44 & 69 & 32 & 25 & 93 & 41 \\
\hline 1949 & 90 & $\ldots$ & 84 & 49 & 50 & 60 & 26 & 27 & 32 & 41 \\
\hline 1950 & 79 & 115 & 83 & 48 & 57 & 71 & 37 & 81 & 30 & 46 \\
\hline
\end{tabular}

\begin{tabular}{|c|c|c|c|c|c|c|c|c|c|c|}
\hline \multirow{2}{*}{ Año } & \multicolumn{2}{|c|}{ Paraguay } & \multicolumn{2}{|c|}{ Perú } & \multicolumn{2}{|c|}{$\begin{array}{c}\text { República } \\
\text { Dominicana }\end{array}$} & \multicolumn{2}{|c|}{ Uruguay } & \multicolumn{2}{|c|}{ Venezuela } \\
\hline & $\begin{array}{l}\text { Exporta- } \\
\text { ciones }\end{array}$ & $\begin{array}{l}\text { Importa- } \\
\text { ciones }\end{array}$ & $\begin{array}{c}\text { Exporta- } \\
\text { ciones : }\end{array}$ & $\begin{array}{l}\text { Importa- } \\
\text { ciones }\end{array}$ & $\begin{array}{l}\text { Exporta- } \\
\text { ciones }\end{array}$ & $\begin{array}{l}\text { Importa- } \\
\text { ciones }\end{array}$ & $\begin{array}{l}\text { Exporta- } \\
\text { ciones }\end{array}$ & $\begin{array}{l}\text { Imporla- } \\
\text { ciones }\end{array}$ & $\begin{array}{l}\text { Exporta- } \\
\text { ciones }\end{array}$ & $\begin{array}{l}\text { Importa- } \\
\text { ciones }\end{array}$ \\
\hline 1928 & $\ldots$ & $\cdots$ & 34 & $\ldots$ & $\cdots$ & $\cdots$ & $\cdots$ & $\cdots$ & 10 & 41 \\
\hline 1929 & $\ldots$ & $\cdots$ & 37 & 30 & $\ldots$ & $\ldots$ & $\ldots$ & $\ldots$ & 10 & 41 \\
\hline 1930 & $\cdots$ & $\ldots$ & 34 & 22 & 49 & 22 & $\ldots$ & $\cdots$ & 12 & 38 \\
\hline 1931 & $\ldots$ & $\ldots$ & 30 & 15 & 45 & 18 & $\ldots$ & $\ldots$ & 10 & 21 \\
\hline 1932 & $\ldots$ & $\ldots$ & 26 & 11 & 52 & 17 & $\ldots$ & $\cdots$ & 10 & 16 \\
\hline 1933 & $\ldots$ & $\cdots$ & 32 & 12 & 46 & 20 & ... & $\ldots$ & 10 & 20 \\
\hline 1934 & $\cdots$ & $\cdots$ & 38 & 21 & 51 & 19 & $m$ & $\ldots$ & 12 & 17 \\
\hline 1935 & $\ldots$ & $\cdots$ & 40 & 24 & 59 & 19 & 122 & 80 & 12 & 13 \\
\hline 1936 & $\ldots$ & $\ldots$ & 42 & 25 & 62 & 19 & 100 & 94 & 13 & 18 \\
\hline 1937 & $\ldots$ & $\ldots$ & 48 & 27 & 58 & 20 & 112 & 110 & 15 & 26 \\
\hline 1938 & 57 & $\cdots$ & 39 & 27 & 64 & 21 & 107 & 106 & 16 & 28 \\
\hline 1939 & 60 & $\ldots$ & 38 & 25 & 64 & 28 & 113 & 97 & 16 & 32 \\
\hline 1940 & 48 & $\cdots$ & 83 & 24 & 59 & 18 & 111 & 97 & 14 & 29 \\
\hline 1941 & 64 & $\cdots$ & 37 & 25 & 67 & 18 & 110 & 101 & 19 & 22 \\
\hline 1942 & 65 & $\ldots$ & 30 & 19 & 37 & 15 & 64 & 86 & 12 & 14 \\
\hline 1943 & 68 & $\ldots$ & 29 & 22 & 62 & 16 & 118 & 68 & 15 & 13 \\
\hline 1944 & 66 & $\ldots$ & 30 & 26 & 94 & 18 & 111 & 69 & 21 & 29 \\
\hline 1945 & 95 & $\ldots$ & 34 & 26 & 59 & 17 & 126 & 84 & 27 & 37 \\
\hline 1946 & 102 & $\cdots$ & 40 & 32 & 73 & 24 & 121 & 113 & 31 & 52 \\
\hline 1947 & 57 & $\ldots$ & 29 & 36 & 71 & 37 & 99 & 143 & 35 & 88 \\
\hline 1948 & 68 & $\ldots$ & 29 & 33 & 61 & 42 & 97 & 109 & 41 & 117 \\
\hline 1949 & 72 & $\ldots$ & 29 & 38 & 52 & 30 & 106 & 96 & 40 & 115 \\
\hline 1950 & 76 & $\cdots$ & 35 & 39 & 57 & 3 I & 129 & 118 & 45 & 98 \\
\hline
\end{tabular}

Fuente: CEPAL, a base de informaciones oficiales. 
se comprimió $24 \%$ entre 1929 y 1932 , y $26 \%$ entre el primer año y 1933 en América Latina, es decir, respectivamente, casi dos y tres y media veces las declinaciones en el producto interno bruto de la región en esos dos períodos ${ }^{17}$.

Sin embargo, lo más notable de este catastrófico episodio es que la reducción del producto interno bruto latinoamericano no sólo correspondió apenas a una fracción de los masivos efectos de la crisis externa que debió absorber, sino que además fue inferior a la baja de la actividad económica en los países desarrollados, en circunstancias que éstos se autoinfligieron circunstancias mucho menos extremas. El índice de la producción del conjunto de los países industriales disminuyó $17 \%$ entre 1929 y 1933 ; en el mismo lapso, el producto interno bruto latinoameri- cano cayó $13 \%{ }^{18}$. Más aún, la depresión de la producción en el país más decisivo para el comercio regional duplicó con creces la latinoamericana; en efecto, el producto interno bruto de los Estados Unidos bajó más de 29\% en este período. El descenso de la actividad en otras regiones en desarrollo fue leve durante la Gran Depresión, gracias en parte a que debieron absorber efectos externos mucho menos violentos que América Latina. Por ejemplo, si bien el volumen de exportaciones de Asia cayó casi tanto como el de América Latina, su volumen de importacines cayó menos de la mitad que el de ésta entre 1929 y 1933. No obstante, la recuperación ulterior de las economías latinoamericanas fue considerablemente más vigorosa que la de los países desarrollados y la de Asia.

\section{La génesis de la sustitución de importaciones y la recuperación de las economías latinoamericanas}

Varios autores han sostenido que la sustitucion de importaciones en América Latina no comenz 6 con la Gran Depresión, sino mucho antes, tal vez ya en el siglo xix, en las principales economías de la región. No hay dudas de que el proceso de sustitución de importaciones generado por la Gran Depresión de hecho sobrepasó largamente en intensidad $y$ alcance cualquier proceso previo de carácter semejante; sin embargo, también es cierto que efectivamente tuvo lugar una diversi-

1935. ¿Puede caber alguna duda de que la tasa de interés constituye en definitiva la rigidez del precio? (La evolución de los valores unitarios de las exportaciones estadounidenses figuran en B. Eichengreen y P. Portes, op. cit., 1987, cuadro 3, aunque la variación entre 1928 y 1929 se estimó sobre la base de A. Maddison, op. cit., 1982, cuadro E3, y las de América Latina figuran en CEPAL, op. cit., 1976, 14 y cuadros por países).

${ }^{17}$ Este cálculo supone que las relaciones entre las exportaciones y las importaciones y el producto interno bruto de la región fueron $40 \%$ y $50 \%$, respectivamente en 1929 . Por lo demás los cálculos se basan en datos efectivos que aparecen en CEPAL, op. cit., cuadro 4. ficación limitada, gradual e intermitente (de expansión y contracción) de las principales economías latinoamericanas antes de los años treinta. Estos observadores tienen en gran parte razón, pero utilizan argumentos equivocados, pues por lo general insisten en el supuesto papel rector de los aranceles respecto del inicio del proceso de sustitución de importaciones en América Latina.

Más recientemente, en el debate constante acerca de si la relación de precios del intercambio de los países en desarrollo ha experimentado o habrá de experimentar un deterioro secular, los críticos más ortodoxos de las políticas y resultados económicos de América Latina después de la Segunda Guerra Mundial, como I. Little y A. Kruegar ${ }^{19}$, han observado que si la relación de precios del intercambio de los países en desarro-

${ }^{18}$ CEPAL $_{1}$ op. cit, cuadros 3 y 4.

${ }^{19}$ I.M.D. Little, Economic Development, Theory, Policy and International Relations, Nueva York, Basic Books, 1982; A.O. Krueger, Altemative Trade Strategies and Development, Chicago, National Bureau of Economic Research and the University of Chicago Press, 1983. 
llo hubiera experimentado un deterioro secular histórico, éstos se habrian industrializado espontáneamente $\mathrm{y}$, por consiguiente, para fomentar la industrialización no habrían necesitado aranceles proteccionistas ni restricciones comerciales cuantitativas, ni deberían haberlos aplicado en ningún caso, de acuerdo con los principios básicos de la teoría comercial. La conclusión desde luego, es que la relación de precios del intercam. bio de estos países no se ha deteriorado con el tiempo, $o$ bien que las prácticas comerciales restrictivas han significado pérdidas innecesarias de bienestar sin aportar, en relación con la industrialización, ningún avance que no se hubiera producido mediante el libre juego de las fuerzas de mercado.

Sin embargo, la industrialización espontánea es precisamente lo que se produjo en las etapas iniciales de la diversificación de las economías latinoamericanas. En efecto, antes de la Gran Depresión, y especialmente desde 1930 hasta la Guerra de Corea; la sustitución de importaciones en América Latina tuvo esencialmente el carácter de un proceso espontáneo, inducido gradualmente al principio por un deterioro de la relación de precios de intercambio de la región desde fines del siglo xIx hasta el decenio de 1920, y luego violentamente por los masivos trastornos externos que repercutieron en las economías de la región en los años treinta. Aunque las conclusiones sobre una declinación secular de la relación de precios del intercambio de América Latina desde el decenio de 1860 hasta el decenio de 1920 han sido objeto de agudas críticas, la cuestión sigue sin resolver. Se encuentra ampliamente documentado, en cambio el radical y sostenido viraje descendente de la relación de precios del intercambio de América Latina desde los últimos ańos del decenio de 1920 hasta la Guerra de Corea, y la transferencia masiva de recursos de la región a las naciones acreedoras durante los primeros años del decenio de 1930 , tras las inmensas cantidades de capital recibidas durante los años veinte. Sin embargo, cabe abordar dos anomalías evidentes: el enorme vacío en la argumentación crítica neoclásica sobre el proceso de sustitución de importaciones en América Latina y la acumulación progresiva de prácticas comerciales restrictivas en la región después de la Guerra de Corea. La primera de estas anomalías motiva las reflexiones que siguen.

\section{El papel catalizador de \\ los trastornos externos}

En primer lugar procede un breve examen de los hechos. Si la relación de precios del intercambio de América Latina en 1928 se considera igual a 100 , el punto de mayor deterioro se alcanzó en 1933, cuando el índice llegó a poco menos de $53^{20}$. Este descenso reflejaba una calda de más del $70 \%$ en el precio promedio de las exportaciones de la región y de alrededor de $21 \%$ en el precio promedio de sus importaciones (cuadro $3)^{21}$.

Entre 1933 y 1937 la relación de precios del intercambio de la región registró una recuperación sostenida, pero continuó muy por debajo del nivel de 1928. En los tres años siguientes se produjo un nuevo deterioro, menos intenso, de modo que al comienzo de la Segunda Guerra Mundial el índice era de $67 \%$, en relación con su nivel de 1928. En el transcurso de la guerra tuvo fluctuaciones; en 1945 era algo más alto que cinco años antes. Como consecuencia de la prosperidad de la posguerra, se recupero con fuerza. Sin embargo, cuando estalló la Guerra de Corea se mantuvo en niveles alrededor de $7 \%$ inferiores al de 1928. Y desde entonces hasta mediados del decenio de 1970 , la relación de precios del intercambio de la región mostró descensos graduales casi año tras año.

En primer lugar, este deterioro excepcionalmente pronunciado y en su mayor parte prolongado (es decir, hasta el final de la Segunda Guerra Mundial) de la relación de precios del inter-

\footnotetext{
${ }^{20} \mathrm{~A}$ este respecto cabe tener presente que desde 1919 / 1920 hasta 1928 los precios internacionales relativos de los principales productos primarios bajaron alrededor de $20 \%$; es decir, en el año 1928, la relación de precios del intercambio de América Latina estaba muy por debajo de los máximos históricos previos.

${ }^{21}$ Los datos fueron calculados por la CEPAL, y se conformaron sobre la base de dos indices. Para el período 1928 1970 las ponderaciones de precios reflejan la estructura de las exportaciones e importaciones de América Latina en 1968; para el periodo 1971-1987 se utilizaron las ponderaciones de precios de 1980. Para los aftos 1928 y 1929 los índices de precios para la región en su totalidad fueron calculados por los autores a partir de los datos disponibles de los países publicados en el estudio de la CEPAL de 1976 (es decir, Argentina, Brasil, Colombia, Chile, Ecuador, El Salvador, México, Perú y Venezuela). En esta publicación los índices de precios regionales fueron calculados desde 1930 en adelante.
} 
cambio de la región alteró directamente los precios relativos internos entre los bienes que poseían extraordinarias ventajas comparativas y todos los demás bienes comerciables, y entre esos productos y los bienes y servicios no comerciados. En efecto, el movimiento observado de la relación de precios del intercambio de la región implicaba directamente una reducción de casi $48 \%$, como promedio, del precio relativo interno de las exportaciones tradicionales. Estos bienes continuaron produciéndose y exportándose, lo que sugiere cuán extraordinaria era su ventaja comparativa, pero también tiene algo que ver con las repercusiones indirectas de la disminución de los precios internacionales relativos de los productos primarios sobre los precios relativos internos.

Así, del mismo modo que un aumento del precio internacional relativo de un producto básico (o un aumento "autónomo" de su rentabilidad) puede iniciar un auge de las exportaciones y provocar una serie de ajustes de cantidad y precios internos, una baja importante y sostenida del precio internacional relativo de una exportación antes floreciente conduce, a la inversa, a una disminución proporcional del ingreso interno y, por lo tanto, a un exceso de oferta de bienes y servicios no comerciables, asi como de bienes comerciables, a los precios relativos internos imperantes. Como resultado, disminuye el precio nominal de los bienes y servicios no comerciados y mejora la balanza comercial en otros bienes comerciables. La caida original del precio interno relativo del producto básico antes floreciente se compensa, en parte, de este modo por este efecto real indirecto (es decir, de gasto) de la involución del auge. Por otra parte, el efecto gasto aumenta aún más el precio relativo interno de otros bienes comerciables, de modo que tanto la repercusión directa como esta repercusión real indirecta del deterioro de la relación de precios del intercambio aumentan la rentabilidad de la producción interna de estos bienes a expensas de la rentabilidad en el resto de la economía. Simultáneamente, el efecto movimiento de recursos comprime aún más la rentabilidad en los sectores productores de exportaciones primarias tradicionales y bienes y servicios no comerciados.

La medida en que el efecto gasto compensa la baja directa del precio relativo interno de los productos de exportación derivados del despla- zamiento de los precios internacionales relativos depende de las intensidades relativas de factores de las funciones de producción de los diversos sectores. Sin embargo, cuando los precios relativos internacionales se deterioran, el precio relativo interno de las exportaciones primarias tradicionales normalmente debe caer, ya que los precios nominales de otros bienes comerciables aumentan a causa de los efectos directos y de gasto.

Además de las repercusiones directas $\mathbf{e}$ indirectas del colapso de los precios internacionales de los productos básicos, el efecto monetario del consiguiente deterioro radical de los balances de la cuenta comercial de las economías latinoamericanas tuvo también un poderoso efecto indirecto sobre los precios relativos internos. Así, al igual que el efecto gasto, aumentó el precio relativo interno de los bienes comerciables, con lo cual también se compensó parcialmente la disminución directa del precio relativo interno de las exportaciones de bienes tradicionales, aument $\delta$ aún más la rentabilidad de la producción de otros bienes comerciables y además hizo bajar los precios nominales de los bienes y servicios no comerciados. De nuevo, sin embargo, tales ajustes monetarios inducidos tienen intrínsecamente el carácter de fenómenos transitorios.

Además, los efectos de gasto y monetarios, ambos depresivos, fueron exacerbados por el violento cambio de dirección de las transferencias de recursos. En efecto, el increfble aumento en el tipo de interés internacional real expost y la repatriación masiva de capital extranjero en la primera mitad del decenio de 1930 superpusieron a los ajustes inducidos mediante la cuenta comercial otro ajuste importante de precios relativos internos, de carácter análogo. Cabría haber supuesto que los trastornos sufridos por la cuenta de capital fueran transitorios, pero éste en particular persistió hasta bien entrada la época posterior a la Segunda Guerra Mundial.

Finalmente, la reducción del volumen de exportaciones de la región, producida por la deflación drástica y las masivas restricciones comerciales cuantitativas en los paises desarrollados, tuvo también su contraparte en un ajuste de los precios relativos internos.

Para varios paises latinoamericanos la crisis estall 6 ya en 1928 , cuando los bancos estadounidenses redujeron drásticamente sus préstamos al exterior para participar en el auge del mercado 
de valores de Nueva York. En ese momento, o poco tiempo después, la mayoría de las economías de la región no pudieron seguir afrontando los efectos de los ya deprimidos precios internacionales de los productos básicos y a la vez expandiendo la absorción interna. Asimismo, el sentimiento proteccionista de los paises desarrollados se había traducido para entonces en considerables alzas arancelarias y en restricciones comerciales cuantitativas cada vez mayores, mientras el aumento de los tipos de interés en los Estados Unidos, provocado por el efecto de burbuja de la bolsa de valores, había aumentado considerablemente los pagos por concepto de intereses de la deuda externa de la región. A fines de 1929, Argentina y Uruguay se apartaron del patrón oro, y muchos otros paises hicieron lo mismo en 1930 y 1931. Para 1933, cuando se habian alcanzado las profundidades de la Gran Depresión, en la totalidad de los paises latinoamericanos o se había abandonado el patrón oro y se hablan efectuado importantes devaluaciones, o bien se seguía aplicando un tipo de cambio fijo, pero a un nivel efectivo real más alto que el que habría regido en otras circunstancias, ya que mantenian la paridad con un dólar estadounidense que habfa sido devaluado en $41 \%$ entre principios de 1933 y principios de $1934^{22}$.

Así, al final, todos los gobiernos latinoamericanos abandonaron el proceso automático de ajuste del patrón oro, a fin de no incurrir en la totalidad de las enormes pérdidas de bienestar que habría acarreado la sola reducción del $50 \%$ del nivel de los precios internos debida al efecto directo del deterioro de la relación de precios del intercambio de la región. Sin embargo, unos pocos perseveraron hasta que el público prácticamente doblegó la guardia de palacio.

Desde luego, es teóricamente posible reestablecer un tipo de cambio real de equilibrio mediante la deflación del nivel de precios internos; pero mientras más grandes sean la intensidad y la duración de los trastornos externos o más rígidos sean los precios internos, mayores serán las caídas del producto si el tipo de cambio nominal permanece fijo. Por otra parte, si se permite que el tipo de cambio se ajuste libremente a los cam-

${ }^{22} \mathrm{La}$ secuencia de acontecimientos es descrita concisamente en B. Eichengreen y J. Sachs, op. cit., 1985. bios bruscos de precios externos, como los que enfrentó América Latina en la Gran Depresión, o si se le modifica rápidamente, aproximándolo al nuevo nivel de equilibrio (o en lo posible haciéndolo coincidir con él), se pueden limitar o incluso evitar las pérdidas innecesarias de bienestar. En ambos casos, los precios relativos internos finalmente se estabilizarán en un valor compatible con el equilibrio macroeconómico ${ }^{23}$.

De este modo, al comparar los datos sobre la evolución de los precios internacionales, los tipos de cambio y los precios internos ${ }^{24}$, podemos medir de modo preliminar el alcance, y en forma precisa la dirección, de los cambios de precios relativos inducidos en las economías latinoamericanas por la Gran Depresión; por lo tanto, también el ámbito del cambio estructural.

Inicialmente se aborda el caso brasileño, ya que la evolución de su relación de precios del intercambio fue en general representativa de las

\footnotetext{
${ }^{23}$ Sin embargo, existe en el proceso de ajuste automático, ya sea basado en el patrón oro 0 , como en tiempos más recientes, en el enfoque monetario del balance de pagos, un defecto fundamental que necesariamente lo hace más oneroso que un proceso de ajuste basado en un tjpo de cambio nominal flexible, aún en una economía enteramente libre de distorsiones de precios. En efecto, un proceso de ajuste automático inevitablemente genera mayores pérdidas de bienestar innecesarias que un proceso promovido mediante un tipo de cambio nominal flexible, porque, incluso en el límite, el tipo de interes nominal no puede bajar a menos de cero. Por consiguiente, a medida que el nivel de precios internos se deflacta, el tipo de interés real debe elevarse a un nivel incom. patible con el equilibrio interno. Los defensores del ajuste automático podrían argumentar que si los precios de los bienes y todos los demás factores fuesen instantáneamente flexibles, no tendría importancia que finalmente el tipo de interés nominal fuera inflexible a la baja. Sin embargo, hay que ser honrados: por flexibles que sean todos los precios, todo tiene lugar en el tiempo.

${ }^{24}$ Antes de proceder a comentar los datos del cuadro 4 corresponde hacer varias advertencias. En primer lugar, si bien la evolución de los precios internacionales relativos muestra variaciones con respecto al año base (es decir, 1963), $e$ indican así aproximadamente los órdenes de magnitud de la rentabilidad de la proclucción interna de las exportaciones y las importaciones, en relación recíproca, el indice global de precios internos íy por lo tanto el índice de precios internos, segứn el supuesto de un país pequeño) se fijó igual al internacional de exportaciones para el perfodo $1925 / 1929$ (es decir, a 100). Este procedimiento se aplicó tanto para permitir una transformación consecuente de los precios internacionales en precios internos como para reflejar el hecho de que antes de la Gran Depresión la rentabilidad de la producción de otros bienes comerciables era forzosamente inferior a la de los
} 
tendencias a nivel regional. Entre 1928/1929 y 1935/1939, el precio promedio de las exportaciones del Brasil cayo $73 \%$. Sin embargo, como resultado de los efectos directos e indirectos de los múltiples trastornos de la situación externa. cuyas repercusiones, una vez abandonado el patrón oro, se manifestaron principalmente en un alza importante del tipo de cambio, y no una disminución de los precios internos, la baja del promedio de los precios internos de sus exportaciones tradicionales fue considerablemente menor, es decir, $40 \%$ (cuadro 4). Por otra parte, los promedios de los precios internos de otros bienes comerciables aumentaron $20 \%$ a pesar de la reducción de $65 \%$ en el promedio de los precios internacionales de estos bienes, mientras que el promedio de los precios internos de los bienes y servicios no comerciados disminuyó $3 \%$ en el conjunto del período. Debido a los cambios de precios internos inducidos por la Gran Depre-

bienes y servicios que no eran comerciados. Sin embargo, $\sin$ duda exagera la rentabilidad de la producción de bienes no comerciables en relación con la de otros bienes comerciables. Además, dado que la rentabilidad de la producción de exportaciones fue por regla general considerablemente mayor que en los bienes no comerciables, este método impide cualesquiera conclusiones en cuanto a un posible desplazamiento de la rentabilidad relativa entre estos dos sectores en el transcurso de los años treinta, aunque desde luego permite la observacion de cambios en precios relativos entre ellos. El tipo de cambio nominal se fjjó también igual a 100 en 1925/ 1929 para llevar a cabo la transformacion de los precios internacionales en precios nacionales. Por consiguiente, en el perlodo base, la relación entre los precios nacionales y los precios internacionales, así como el cambio real, por lo general no equivalen a 100 , pero esto no reviste mayor importan. cia. Cabe observar, asimismo, que se utilizaron los precios internacionales de las importaciones como indicador de los precios internacionales de otros bienes comerciables y se transformaron en los ptecios internos correspondientes según el supuesto del país dependiente), y el Indice de precios internos al consumidor se tomó como el precio de los bienes y servicios no comerciados. El primer procedimiento es enteramente satisfactorio; no sucede lo mismo con el segundo, ya que los bienes comerciables entraron en los indices de precios internos al consumidor. Sin embargo, en este caso no se disponia de otra opción. Por último, al efectuar la transformación de precios internacionales en precios internos no se ha tomado en cuenta la incidencia de cualesquiera distorsiones de precios inducidas por politicas internas, entre etlas los tipos de cambio máltiples (es decir, se utilizaron los tipos de cambio de importación, que fueron los únicos de que se dispuso constantemente). sión, el promedio de los precios internos de las exportaciones tradicionales disminuy $60 \%$ con respecto al promedio de los precios internos de otros bienes comerciables, y alrededor de $40 \%$ respecto del de los bienes y servicios no comerciados. Cabe observar particularmente que el promedio de los precios internos de las exportaciones tradicionales superó en $55 \%$ al de otros bienes comerciables en $1928 / 1929$, pero fue $23 \%$ más bajo que el promedio de los precios internos de otros bienes comerciables en 1935/1939.

El cambio en la relación entre los precios internos y los de las exportaciones tradicionales y otros bienes comerciables registró magnitudes más o menos similares en Perú y Colombia. Mientras en el primero el promedio del precio interno de las exportaciones tradicionales fue un $52 \%$ más alto que el de otros bienes comerciables en 1928/1929, fue inferior al de estos bienes en $17 \%$ durante $1935 / 1939$. Las cifras correspondientes para Colombia fueron $+50 \%$ y $-11 \%$.

La disminución del valor unitario de las exportaciones de Chile no fue mucho menor que la de los países antes mencionados; no obstante, debido a un aumento mucho mayor del tipo de cambio, el precio interno promedio de sus exportaciones de hecho aumentó más de $70 \%$ en la primera mitad del decenio de 1930 y permaneció $25 \%$ por sobre el nivel de $1925 / 1929$ en el periodo 1935/1939. Al mismo tiempo, debido a que en vísperas de la Gran Depresión su relación de precios del intercambio era especialmente favorable, en 1935/1939 el precio interno promedio de otros bienes comerciables se mantenía aún cerca de $18 \%$ por sobre el precio interno promedio de las exportaciones tradicionales en el mismo período, a pesar del deterioro de $51 \%$ de su relación de precios de intercambio. Sin embargo, el aumento del precio interno de otros bienes comerciables durante este periodo fue pronunciado: superó la cifra de $50 \%$. Por otra parte, Chile fue el único pais en que el precio de los bienes y servicios no comerciados disminuyó en relación con el precio medio de las exportaciones tradicionales en este período, debido, nuevamente, a la devaluación excepcionalmente grande de su moneda, entre 1928/1929 y 1930/1934. En este último período, el precio relativo de los bienes y servicios no comerciados, en términos de exportaciones, fue inferior en $34 \%$ al de 1928 / 1929. Sin embargo, en el período subsiguiente de 
Cuadro 4

AMERICA LATINA: FORMACION Y EVOLUCION DE LOS PRECIOS INTERNOS RELATIVOS EN ALGUNOS PAISES, 1925/1929-1935/1939 $(\text { Indices })^{\mathrm{a}}$

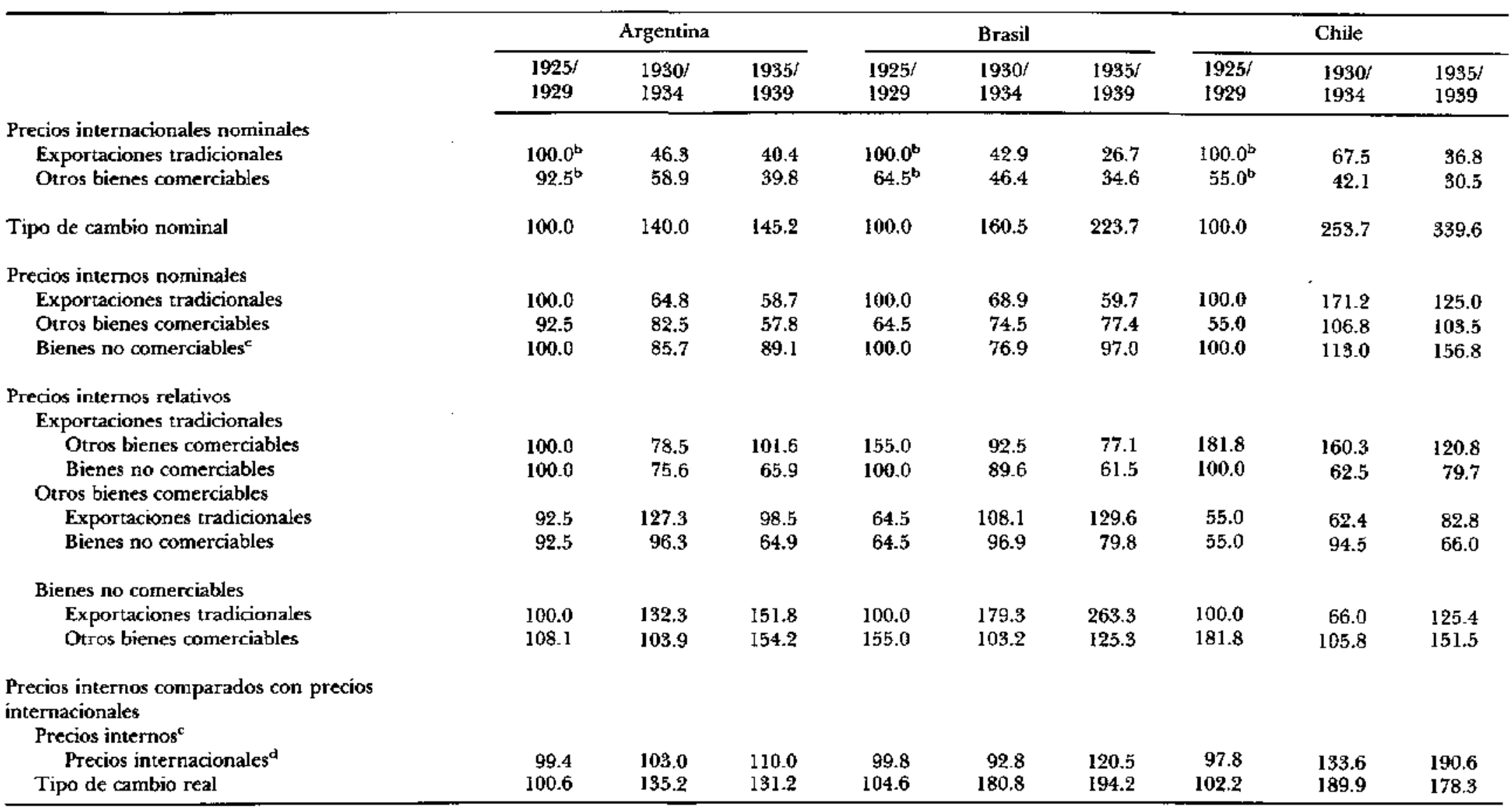




\begin{tabular}{|c|c|c|c|c|c|c|c|c|c|}
\hline & \multicolumn{3}{|c|}{ Colombia } & \multicolumn{3}{|c|}{ México } & \multicolumn{3}{|c|}{ Perú } \\
\hline & $\begin{array}{l}1925 / \\
1929\end{array}$ & $\begin{array}{l}1930 / \\
1984\end{array}$ & $\begin{array}{l}1935 / \\
1939\end{array}$ & $\begin{array}{l}1925 / \\
1929\end{array}$ & $\begin{array}{l}1930 / \\
1934\end{array}$ & $\begin{array}{l}1935 / \\
1999\end{array}$ & $\begin{array}{l}1925 / \\
1929\end{array}$ & $\begin{array}{l}1930 / \\
1934\end{array}$ & $\begin{array}{l}1935 / \\
1939\end{array}$ \\
\hline \multicolumn{10}{|l|}{ Precios internacionales nominales } \\
\hline Exportaciones tradicionales & $100.0^{\mathrm{b}}$ & 51.9 & 29.4 & $100.0^{\mathrm{b}}$ & 55.7 & 52.3 & $1000^{\mathrm{b}}$ & 41.9 & 25.3 \\
\hline Otros bienes comerciables & $66.5^{b}$ & 43.4 & 33.0 & $101.1^{\mathrm{b}}$ & 83.0 & 59.2 & $65.7^{\mathrm{b}}$ & 42.6 & 30.6 \\
\hline Tipo de cambio nominal & 100.0 & 115.7 & 177.7 & 100.0 & 145.5 & 196.5 & 100.0 & 155.6 & 168.9 \\
\hline \multicolumn{10}{|l|}{ Precios internos nominales } \\
\hline Exportaciones tradicionales & 100.0 & 60.0 & 52.2 & 100.0 & 81.0 & 102.8 & 100.0 & 65.2 & 42.7 \\
\hline Otros bienes comerciables & 66.5 & 48.4 & 58.6 & $10 \mathrm{I} .1$ & 120.8 & 116.3 & 65.7 & 66.3 & 51.7 \\
\hline Bienes no comerciables ${ }^{e}$ & 100.0 & 65.9 & 89.1 & 100.0 & 91.0 & 116.4 & 100.0 & 82.5 & 87.5 \\
\hline \multicolumn{10}{|l|}{ Precios internos relativos } \\
\hline \multicolumn{10}{|l|}{ Exportaciones tradicionales } \\
\hline Otros bienes comerciables & 150.4 & 124.0 & 59.1 & 98.9 & 67.0 & 88.4 & 152.2 & 98.3 & 82.6 \\
\hline Bienes no comerciables & 100.0 & 91.0 & 58.6 & 100.0 & 89.0 & 88.3 & 100.0 & 79.0 & 48.8 \\
\hline \multicolumn{10}{|l|}{ Otros bienes comerciables } \\
\hline Exportaciones tradicionales & 66.5 & 80.7 & 112.3 & 101.1 & 149.1 & 113.1 & 65.7 & 101.7 & 121.1 \\
\hline Bienes no comerciables & 66.5 & 79.4 & 65.8 & 101.1 & 182.7 & 99.9 & 65.7 & 80.3 & 59.1 \\
\hline \multicolumn{10}{|l|}{ Bienes no comerciables } \\
\hline Exportaciones tradicionales & 100.0 & 109.8 & 170.7 & 100.0 & 112.3 & 113.2 & 100.0 & 126.5 & 204.9 \\
\hline Otros bienes comerciables & 150.3 & 136.2 & 152.1 & 98.9 & 75.3 & 1008 & 152.2 & 124.4 & 169.2 \\
\hline \multirow{2}{*}{\multicolumn{10}{|c|}{$\begin{array}{l}\text { Prexios internos comparados con precios } \\
\text { internacionales } \\
\text { Precios internos }\end{array}$}} \\
\hline & & & & & & & & & \\
\hline Precios internacionales $^{d}$ & 100.0 & 78.5 & 110.7 & 94.4 & 103.8 & 136.5 & 105.1 & 104.8 & 114.3 \\
\hline Tipo de cambio real & 100.0 & 147.4 & 160.5 & 105.9 & 132.4 & 135.9 & 95.2 & 148.5 & 147.8 \\
\hline
\end{tabular}

Fuente: Para los precios internacionales de las exportaciones tradicionales y otros bienes comerciables, que son los pertinentes para las exportaciones e importaciones, respectivamente, de cada país, véase CEPAl, America Latina: relación de precias del intercambio, op. cit., 1976, cuadros por países; para los tipos de cambio y los precios internos, véase C. Díaz-Alejandro "Latin America in Depression, 1929-1989", The theory and experience of economic development (Essays in honour of Sir W. Arthur Lewis), M. Gersowitz y otros (comps.), Londres: George Allen y Unwin, 1982, cuadros 20.4 y 20.5.

* Precio medio de las exportaciones tradicionales (ponderaciones de precios de 1963) en 1928/1929=100, y tipo de cambio nominal medio en 1925/ $1929=100$.

b $1928 / 1929$.

c Indice nacional de precios al consumidor.

d Indice de precios al consumidor de los Estados Unidos. 
cuatro años el precio de los bienes no comerciables en relación con el de las exportaciones casi se duplicó, mientras subía vertiginosamente el nivel de precios internos, disminuía en otro tercio el precio unitario de las exportaciones y se reducía el ritmo de devaluacion. Del mismo modo, el precio interno de otros bienes comerciables, en relación con los de bienes no comerciables, se elevó bruscamente ( $72 \%$ ) en la primera parte del decenio de 1930. pero después volvió a disminuir alrededor de $30 \%$ en la última parte del decenio.

La reducción en el precio internacional de las exportaciones de México fue apreciablemente menor que en los casos antes mencionados. Sin embargo, dado que su relación de precios del intercambio estaba aproximadamente a la par con el año base (1963) en 1928/1929, el precio interno de otros bienes comerciables, en relación con el de sus exportaciones, se elevó alrededor de $12 \%$ en los años treinta. Como en los demás países de la región, el precio interno de otros bienes comerciables en relación con el de bienes y servicios no comerciados aumentó marcadamente en la primera mitad del decenio de 1930 , pero ulteriormente disminuyó a medida que el precio internacional de otros bienes comerciables continuó bajando, la relación de precios del intercambio se recuperó parcialmente y el tipo de cambio real se estabilizó.

La principal excepción con respecto a estas tendencias se presentó en Argentina. En efecto, aunque los precios internacionales de las exportaciones argentinas por supuesto disminuyeron durante el período, ya en la segunda mitad del decenio de 1930 hubo una gran recuperacion en su relación de precios del intercambio, tras el revés sufrido a comienzos del decenio. Esto se debió en gran medida a su privilegiado acceso al mercado británico protegido, con arreglo a las disposiciones del Tratado Runciman, de 1934. Por consiguiente, fue el único país en que a fines del decenio de 1930 el precio interno de otros bienes comerciables en relación con el de productos de exportación no estuvo sustancialmente por encima del nivel de 1928/1929. Del mismo modo, el ajuste del tipo de cambio fue notoriamente menos marcado que en el resto de los paises respecto de los cuales se obtuvieron datos comparativos. Durante este período, por lo tanto, los cambios de precios nominales incidieron principalmente en el aumento del precio de los bienes no comerciables en relación con el de los comerciables.

Desde luego los cambios masivos en los precios relativos internos, provocados por la Gran Depresión, estimularon poderosamente la reasignación hacia el resto de la economía de los recursos del sector productor de los bienes anteriormente en auge. Esto sucedio con independencia de las iniciativas de política interna, aunque, según se verá, la política económica en América Latina en general reforzó el cambio estructural, pero sin introducir distorsiones importantes en los precios internos.

En efecto, al comparar los cambios en los precios relativos internos, puede apreciarse el siguiente patrón. En Brasil, el precio interno de otros bienes comerciables, en relación con el de las exportaciones tradicionales, se duplico con creces entre 1928/1929 y 1935/1939; en el Perú se elevó aceleradamente más de $84 \%$; en Colombia subió $69 \%$; en Chile creció más de $50 \%$, y en México, 13\%. La única excepción se registró en Argentina, donde disminuyó alrededor de $6 \%$.

En el mismo período, el precio interno de los bienes y servicios no comerciados, en relación con el de las exportaciones tradicionales, subió vertiginosamente $163 \%$ en el Brasil; aumentó a más del doble en el Perú, y se elevó alrededor de $71 \%$ en Colombia, $52 \%$ en Argentina, $25 \%$ en Chile y $13 \%$ en México.

Además, tanto en el Brasil como en Chile, el precio interno de otros bienes comerciables, en relación con el de bienes y servicios no comerciados, aumentó en forma considerable durante este período, a pesar de la drástica disminución de los precios internacionales de otros bienes comerciables, y debido a los aumentos especialmente grandes del tipo de cambio en esos dos países. En Colombia y México el precio interno relativo de otros bienes comerciables, en términos de bienes y servicios no comerciados, apenas cambió desde los años previos a la Gran Depresión hasta fines del decenio de 1930. En el Perú disminuyó $10 \%$ y en Argentina casi $30 \%$ debido, nuevamente, a la menor influencia de los trastornos externos en este pafs y, al consiguiente ajuste proporcionalmente menor de su tipo de cambio (cuadro 4).

Si bien la génesis del cambio estructural en las economías latinoamericanas que trajo consigo la Gran Deppresión fue de enormes proporciones 
(en algunos países concentrada en los otros bienes comerciables, en otros, en bienes no comerciables), también hubo un aporte de las políticas económicas internas a la reasignación de recursos.

\section{La contribución de la politica interna}

En efecto, los datos disponibles sobre precios y tipos de cambio no bastan para explicar por sí solos la magnitud de la declinación del precio interno relativo de las exportaciones tradicionales ni del de otros bienes comerciables. En particular, el uso de regímenes de tipos de cambio múltiples, que discriminaban contra las exportaciones tradicionales, y de restricciones comerciales cuantitativas, que discriminaban contra las importaciones "no esenciales", aumentó la salida de recursos del primer sector y los encauzó hacia la producción de otros bienes comerciables. Aunque se carece de información comparativa precisa sobre regímenes de tipos de cambio múltiples y restricciones comerciales cuantitativas para los anos treinta, los datos pertinentes respecto de la situación imperante alrededor de 1950 pueden ser indicativos de la incidencia de estas políticas en el periodo anterior. Sin embargo, cabe tener presente que en general el hecho de recurrir a tipos de cambio múltiples y a restricciones cuantitativas al comercio, se intensificó en forma gradual durante este periodo en varios paises, y aumentó en gran medida en otros (por ejemplo, en Argentina, a mediados y a fines del decenio de 1940).

\section{a) Políticas comerciales}

Teniendo presentes estas advertencias, cabe señalar que en Argentina el margen entre el tipo de cambio oficial para las importaciones no esenciales y para las exportaciones tradicionales fue casi $190 \%$ en torno al año 1950 ; por su parte el margen entre las importaciones no esenciales, por un lado, y las importaciones esenciales $y$ las exportaciones no tradicionales, por otro, fue $92 \%$ (cuadro 5$)^{2.5}$ y en Chile, la diferencia entre las importaciones no esenciales y las exportacio-

\footnotetext{
${ }^{25}$ En contraste, en $1934 / 1936$ el margen entre los tipos de cambio medios para importaciones y exportaciones en la Argentina fue alrededor de 12\% (C. Dlaz-Alejandro, "Latin America in depression 1929-1939", The Theory and Experience
}

nes tradicionales fue $174 \%$, mientras que el margen entre estas importaciones y las esenciales estuvo en torno de $39 \%$. El tipo de cambio oficial, sin embargo, fue el mismo para las exportaciones no tradicionales y las importaciones no esenciales; así, había iguales incentivos para la producción de otros bienes comerciables, salvo los de capital e intermedios susceptibles de importarse. Pueden apreciarse también márgenes considerables en Costa Rica, Paraguay, Ecuador y Uruguay.

Por otra parte, en países como Brasil, Colombia, Perú, Venezuela y Nicaragua, el campo de aplicación de los tipos de cambio múltiples fue más bien limitado. En el Brasil los márgenes fueron pocos y marginales; en Colombia predominó casi el mismo patrón, con una excepción notable: el uso para las exportaciones no tradicionales de un tipo de cambio superior en $23 \%$ al de las importaciones no esenciales. En Venezuela, hubo un pequeño margen entre el tipo de cambio para importaciones no esenciales y el tipo de cambio para el resto de las operaciones; en Perú, un solo tipo de cambio para todas las partidas de la cuenta corriente (cuadro 5). Finalmente, en Cuba, El Salvador, Guatemala, Haití, México y Panamá se utilizo un tipo de cambio para todas las transacciones (cuadro 6).

No disponemos de información cuantitativa sobre las restricciones administrativas al comercio. Sin embargo, entre los 18 países de la región respecto de los cuales se dispone de datos cualitativos, trece empleaban alrededor de 1950 , prohibiciones o licencias de importación; cinco de los 12 países sobre los cuales se obtuvo información exigían depósitos previos para las importaciones (cuadro 6).

Como puede apreciarse, la mayoría de los países latinoamericanos aplicaban restricciones comerciales cuantitativas a comienzos del período posterior a la Segunda Guerra Mundial (y tal vez antes). No obstante, y contra lo que suele creerse, no se utilizaron los aranceles para faciljtar el ajuste a la Gran Depresión. Los de importación fueron, en promedio, entre $23 \%$ y $30 \%$ en los países latinoamericanos más grandes, en los

of Economic Development: Essays in Honor of ST. W. Arthur Lewis, M. Gersovitz y otros (comp.). Londres, George Allen y Unwin, 1982 (cuadro 20.6). 
Cuadro 5

AMERICA LATINA: REGIMENES DE TIPO DE CAMBIO EN ALGUNOS PAISES ALREDEDOR DE 1950

\begin{tabular}{|c|c|c|c|c|c|}
\hline Pais & $\begin{array}{l}\text { Importaciones } \\
\text { esenciales }\end{array}$ & $\begin{array}{c}\text { Importaciones no } \\
\text { esenciales }\end{array}$ & $\begin{array}{c}\text { Exportaciones } \\
\text { básicas }\end{array}$ & $\begin{array}{l}\text { Exportaciones no } \\
\text { tradicionales }\end{array}$ & $\begin{array}{l}\text { Cuenta de } \\
\text { capital }\end{array}$ \\
\hline Argentina ${ }^{a}$ & 7.5 & 14.4 & 5.0 & 7.5 & 14.4 \\
\hline Bolivia & 42.4 & 56.1 & 55.5 & 42.0 & 42.4 \\
\hline Brasil $^{c}$ & 18.7 & 19.7 & 18.4 & 18.4 & 18.7 \\
\hline Colombia* & 2.2 & 2.6 & 2.0 & 3.2 & 2.0 \\
\hline Costa Ricad & 9.4 & 14.5 & 5.6 & 5.6 & 6.2 \\
\hline Chile $^{a}$ & 31.1 & 43.1 & 19.4 & 43.0 & 48.1 \\
\hline Ecuador & 15.2 & 25,0 & 15.0 & 18.3 & 13.5 \\
\hline Nicaragua ${ }^{r}$ & 5.0 & 6.9 & 5.0 & 5.0 & 5.0 \\
\hline Paraguayb & 3.1 & 8.1 & 4.9 & 6.0 & 8.1 \\
\hline Perút & 14.8 & 14.8 & 14.8 & 14.8 & 16.3 \\
\hline Uruguay $^{\mathbf{a}}$ & 1.9 & 2.5 & 1.5 & 2.4 & 3.1 \\
\hline Venezuela' & 3.1 & 3.4 & 3.3 & 3.3 & 3.3 \\
\hline
\end{tabular}

Fuente: Fondo Monetario Internacional, Annual Report on Exchange Restrictions, 1950-1952.

a Pesos por dólar de los Estados Unidos.

bolivianos por dólar de los Estados Unidos.

c Cruceiros por dólar de los Estados Unidos.

a Colones por dólar de los Estados Unidos.

- Sucres por dólar de los Estados Unidos.

- Córdovas por dólar de los Estados Unidos.

g Guaraníes por dólar de los Estados Unidos.

h Soles por dólar de los Estados Unidos.

i Bolívares por dólar de los Estados Unidos.

Cuadto 6

AMERICA LATINA: SINTESIS DE LAS RESTRICCIONES GUANTITATIVAS

AL. COMERCIO EXTERIOR, ALREDEDOR DE $1950^{\circ}$

\begin{tabular}{lcccc}
\hline País & $\begin{array}{c}\text { Tipos de } \\
\text { cambio } \\
\text { múltiples }\end{array}$ & $\begin{array}{c}\text { Controles } \\
\text { de } \\
\text { cambio }\end{array}$ & $\begin{array}{c}\text { Restricciones } \\
\text { cuantitativas }\end{array}$ & $\begin{array}{c}\text { Depósitos } \\
\text { previos }\end{array}$ \\
\hline Argentina & Si & Si & Si & No \\
Bolivia & Sí & Sí & Sí & No \\
Brasil & Si & Sí & Si & No \\
Colombia & Si & Sí & Si & Si \\
Costa Rica & Si & Si & Si & Si \\
Cuba & No & No & No & No \\
Chile & Sí & Sí & Si & No \\
Ecuadot & Si & Sí & Si & Si \\
El Salvador & No & No & No & $\ldots$ \\
Guatemala & No & No & No & $\ldots$ \\
Haití & No & No & No & $\ldots$ \\
México & No & Si & Si & $\ldots$ \\
Nicaragua & Si & Sí & Si & Sí \\
Panamá & No & No & No & $\ldots$ \\
Paraguay & Si & Sí & Si & Si \\
Perú & No & Sí & Si & Si \\
Uruguay & Si & Sí & Si & No \\
Venezuela & Si & Si & Si & No \\
\hline
\end{tabular}

Fuente: CEPAL, a base de informaciones oficiales; Fondo Monetario Internacional.

a Aproximadamente 1948.1950.

h. Prohibiciones de importacion y/o licencias previas para importar. 
últimos años del decenio de 1920, y experimentaron sólo leves aumentos durante los decenios de 1930 y de 1940 . Es más, entre 1925/1927 y $1932 / 1937$ el arancel medio de importación disminuyó de $28 \%$ a $17 \%$ en México y de 26 a alrededor de $24 \%$ en Argentina (cuadro 7). Durante el mismo período aumentó levemente en Colombia, es decir, de $23 \%$ a $25 \%$, y en Chile el arancel general subió de $25-30 \%$ a $35 \%$. En el Brasil, pais respecto del cual no se obtuvieron datos anteriores, el arancel implícito medio era inferior a $26 \%$ en $1936^{26}$.

Además, en el período 1945/1950 el arancel medio habia bajado a $11 \%$ en México, $12 \%$ en la Argentina, $14 \%$ en el Brasil y $17 \%$ en Colombia. En Chile, en cambio, al parecer continuó en alza. El arancel medio aplicado a los bienes de consumo aument $\delta$ de $45 \%$ en el período $1932 / 1937$ a $62 \%$ en el período $1945 / 1950$ (cuadro 7 ).

En general, se puede afirmar provisionalmente que, si bien la política comercial fomentaba claramente el proceso de sustitución de importaciones en América Latina hacia la época en que estallo la Guerra de Corea, su influjo dificilmente puede compararse al papel catalizador desempeñado por los masivos cambios de precios relativos internos provocados por la Gran Depresión en los años treinta. Además, el efecto de estas políticas comerciales discriminatorias en América Latina debe interpretarse a la luz de las considerables distorsiones de precios provocadas en la economía internacional por las políticas comerciales de los paises industriales en los años treinta y los años cuarenta. A este respecto, los niveles arancelarios en América Latina fueron considerablemente inferiores a los impuestos en muchos paises desarrollados en esa época.

El contraste entre la escasa incidencia de las distorsiones de precios debidas a la política comercial en la mayoria de las economias latinoamericanas durante este periodo, por una parte, $y$ la progresiva acumulación de esas distorsiones mientras la economía internacional experimentaba una expansión sin precedentes en la época de posguerra, por otra, contribuye mucho a ex-

\footnotetext{
${ }^{26}$ El único pais respecto del cual tenemos algunos datos sobre la dispersión de los aranceles en los años treinta es Argentina, cuyos aranceles de bienes de consumo fluctuaron entre $23 \%$ y $31 \%$, los de bienes intermedios de 1 al $15 \%$, y los de bienes de capital en promedio $18 \%$.
}

plicar los excepcionales resultados económicos en la región durante el período 1929-1950, y la acumulación incesante de desequilibrios macroeconómicos que se produjo después.

\section{b) Politicas macroeconomicas}

Una de las razones principales por las que América Latina obtuvo mejores resultados que los países desarrollados en los años treinta, a pesar de haberse visto sometida a peores trastornos de origen externo, consistió en un recurso más oportuno a los cambios de precios relativos mediante aplicación de políticas, y en un mayor uso (o tolerancia) de mecanismos de precios para producir los necesarios cambios estructurales.

De este modo, todos los países latinoamericanos de cuyos datos se dispone a fin de cuentas aumentaron la competitividad de sus economias, en relación con los países industrializados, mediante importantes alzas en sus tipos de cambio reales, especialmente en los primeros años del decenio de 1930. Así sucedió sobre todo en paises como Brasil y Chile, donde el tipo de cambio real aumento $94 \%$ y $78 \%$ respectivamente, entre 1925/1929 y 1935/1939 (cuadro 4). Tanto en Colombia como en Uruguay el tipo de cambio real subio alrededor de $60 \%$ en este período ${ }^{27}$; en Perú se elevó 53\%, en México 40\% y en Argentina $33 \%{ }^{28}$.

Los ajustes de precios internos relativos, en proporción a la magnitud de los efectos de trastornos externos, resultaban inevitables, lo que puede comprobarse haciendo referencia a contrastes entre los mismos paises latinoamericanos. Sin embargo, la oportunidad de estos ajustes, y la forma como se dividieron entre los producidos mediante el tipo de cambio real y los generados mediante políticas comerciales discriminatorias, ejercieron una influencia decisiva sobre el grado de perjuicio social innecesario, es decir, sobre la baja de la actividad económica y sobre la rapidez y el alcance de su recuperación.

En general, los principales países latinoamericanos abandonaron mucho antes que los paises

\footnotetext{
${ }^{27}$ Los datos correspondientes a Uruguay han sido tomados de C. Díaz-Alejandro, op. cit., 1982, cuadro 20.4 .

${ }^{28}$ En todos los casos la mayor parte del aumento del tipo de cambio real tuvo lugar en la primera mitad del decenio de 1980 .
} 
Cuadro 7

AMERICA LATINA: EVOLUCION DE LOS ARANCELES NOMINALES EN ALGUNOS PAISES, 1925-1986 (Porcentajes)

\begin{tabular}{|c|c|c|c|c|c|c|c|c|}
\hline País & $1925 / 1927$ & $1932 / 1937$ & $1945 / 1950$ & $1960 / 1965$ & $1967 / 1970$ & $1972 / 1977$ & $1978 / 1981$ & $1982 / 1986$ \\
\hline \multicolumn{9}{|l|}{ Argentina } \\
\hline Promedio & $26.0^{\mathrm{a}}$ & $23.8^{b}$ & $12.2^{i}$ & $148.0^{d}$ & $36.0^{c}$ & $93.7^{\mathbf{f}}$ & $34.4^{\mathrm{g}}$ & $0.0-38.0^{\mathrm{h}}$ \\
\hline Bienes de consumo & $\ldots$ & $22.9-31.4^{\mathrm{b}}$ & ... & $235.0^{\mathrm{d}}$ & $88.0^{\circ}$ & $100.0^{\mathrm{T}}$ & $36.5^{\mathrm{B}}$ & $\ldots$ \\
\hline Bienes intermedios & $\ldots$ & $1.0-15.0^{b}$ & $\ldots$ & $243,0^{\mathrm{t}}$ & $51.0^{\circ}$ & $95.0^{r}$ & $0.0-30.0^{\mathrm{g}}$ & $\ldots$ \\
\hline Bienes de capital & $\cdots$ & $18.4^{b}$ & $\cdots$ & $156,0^{d}$ & $87,0^{\circ}$ & $70.0^{\mathrm{r}}$ & $36.7^{8}$ & $10.0^{\mathrm{h}}$ \\
\hline \multicolumn{9}{|l|}{ Brasil } \\
\hline Promedio & $\cdots$ & $25.6^{i}$ & $14.4^{i}$ & $85.0^{j}$ & $37.0^{\mathrm{i}}$ & $55.1^{2}$ & $99.0^{k}$ & $45.0^{1}$ \\
\hline Bienes de consumo & $\ldots$ & $\ldots$ & $\ldots$ & $132.0^{j}$ & $67.0^{i}$ & $\ldots$ & $\ldots$ & $\cdots$ \\
\hline Bienes intermedios & $\ldots$ & $\cdots$ & $\cdots$ & $70.0^{j}$ & 37.0 & $\ldots$ & $\ldots$ & $\cdots$ \\
\hline Bienes de capital & $\cdots$ & $\cdots$ & $\ldots$ & $56.0^{i}$ & $40.0^{i}$ & $\cdots$ & $\cdots$ & $\ldots$ \\
\hline \multicolumn{9}{|l|}{ Colombia } \\
\hline Promedio & $23.0^{r}$ & $25.0^{+}$ & $17,0^{r}$ & $48.0^{r}$ & $13.0^{\mathrm{c}}$ & $36.0^{5}$ & $28.0^{*}$ & $\cdots$ \\
\hline Bienes de consumo & $\ldots$ & $\ldots$ & 18.0 & 53.0 & $49.0^{\circ}$ & 47.0 & 49.0 &.$\cdots$ \\
\hline Bienes intermedios & $\cdots$ & $\cdots$ & 22,0 & 40.0 & $11.0^{\circ}$ & 24.0 & 22.0 & $\cdots$ \\
\hline Bienes de capital & $\ldots$ & $\cdots$ & $\cdots$ & $\cdots$ & $33.0^{\mathrm{e}}$ & 28.0 & 30.0 & $\cdots$ \\
\hline \multicolumn{9}{|l|}{ Casta Rica } \\
\hline Promedio & $\cdots$ & $\cdots$ & $\cdots$ & $\cdots$ & $\ldots$ & $25.8^{\mathrm{v}}$ & $16.8^{2}$ & $\cdots$ \\
\hline Bienes de consumo & $\ldots$ & $\cdots$ & $\cdots$ & $58.1^{6}$ & $85.5^{\prime \prime}$ & 28.0 & 18.3 & $\cdots$ \\
\hline Bienes intermedios & $\cdots$ & $\ldots$ & $\ldots$ & $28.3^{t}$ & $32.8^{4}$ & 17.3 & 13.0 & $\cdots$ \\
\hline Bienes de capital & $\cdots$ & $\cdots$ & $\cdots$ & $10.0^{\mathrm{c}}$ & $11.8^{\mathrm{u}}$ & 21.0 & 16.3 & $\cdots$ \\
\hline \multicolumn{9}{|l|}{ Chile } \\
\hline Promedio & $25.0-30.0^{\mathrm{m}}$ & $35.0^{\mathrm{n}}$ & - & $89.0^{\circ}$ & $\cdots$ & $94.0-24.0^{\mathrm{P}}$ & $10.0^{4}$ & $20.0^{4}$ \\
\hline Bienes de consumo & $\ldots$ & $45.0^{n}$ & $62.0^{c}$ & $204.0^{\circ}$ & $\ldots$ & $\ldots$ & 10.0 & $\mathbf{2 0 . 0}$ \\
\hline Bienes intermedios & $\ldots$ & - & $3.0^{\mathrm{c}}$ & $53.0^{\circ}$ & $\ldots$ & $\cdots$ & 10.0 & 20.0 \\
\hline Bienes de capital & $\ldots$ & - & $30.0^{c}$ & $92.0^{\circ}$ & $\cdots$ & $\cdots$ & 10.0 & 20.0 \\
\hline \multicolumn{9}{|l|}{ El Salvador } \\
\hline Promedio & $\cdots$ & $\cdots$ & $\cdots$ & $\ldots$ & $\ldots$ & $47.6^{w}$ & $\ldots$ & $\cdots$ \\
\hline Bienes de consumo & $\ldots$ & $\cdots$ & $\cdots$ & $52.2^{4}$ & $79.3^{\mathrm{u}}$ & $32.9^{m}$ & $\cdots$ & $\cdots$ \\
\hline Bienes intermedios & $\ldots$ & $\ldots$ & $\cdots$ & $37.8^{4}$ & $38.1^{\mathrm{u}}$ & $30.4^{w}$ & $\cdots$ & $\cdots$ \\
\hline Bienes de capital & $\ldots$ & $\ldots$ & $\cdots$ & $9.8^{\prime}$ & $10.2^{\mathrm{u}}$ & $10.6^{w}$ & $\cdots$ & $\cdots$ \\
\hline \multicolumn{9}{|l|}{ Guatemala } \\
\hline Promedio & $\cdots$ & $\cdots$ & $\cdots$ & $\ldots$ & $\cdots$ & $50.1^{w}$ & $29.8^{x}$ & $\cdots$ \\
\hline Bienes de consumo & $\cdots$ & $\cdots$ & $\cdots$ & $50.4^{6}$ & $79.8^{\prime \prime}$ & $37.0^{\mathrm{w}}$ & $39.0^{x}$ & $\cdots$ \\
\hline Bienes intermedios & $\ldots$ & $\cdots$ & $\cdots$ & $24.4^{c}$ & $28.6^{u}$ & $26.3^{w}$ & $23.1^{x}$ & $\ldots$ \\
\hline Bienes de capital & $\cdots$ & $\cdots$ & $\cdots$ & $6.0^{t}$ & $10.3^{4}$ & $10.3^{w}$ & $23.3^{x}$ & $\cdots$ \\
\hline \multicolumn{9}{|l|}{ Honduras } \\
\hline Promedio & ... & $\ldots$ & $\cdots$ & $\cdots$ & $\cdots$ & $41.2^{\mathrm{m}}$ & 21,9 & ... \\
\hline Bienes de consumo & $\cdots$ & $\cdots$ & $\cdots$ & $50.0^{t}$ & $91.9^{4}$ & $30.3^{\prime \prime}$ & $\cdots$ & $\cdots$ \\
\hline Bienes intermedios & $\cdots$ & $\cdots$ & $\ldots$ & $31.6^{t}$ & $35.7^{u}$ & $28.9^{w}$ & $\cdots$ & $\cdots$ \\
\hline Bienes de capital & $\ldots$ & $\cdots$ & $\cdots$ & $2.9^{t}$ & $9.9^{u}$ & $5.7^{\mathrm{W}}$ & $\cdots$ & $\ldots$ \\
\hline \multicolumn{9}{|l|}{ México } \\
\hline Promedio & $28.4^{y}$ & $17.0^{y}$ & $11.1^{y}$ & $20.1^{2}$ & $17.7^{\mathrm{aa}}$ & $280^{200}$ & $11.5^{\mathrm{aa}}$ & $26.5^{\mathrm{aa}}$ \\
\hline Bienes de consumo & $\ldots$ & "' & $\ldots$ & $63.9^{2}$ & $\cdots$ & $\cdots$ & $\cdots$ & $\ldots$ \\
\hline Bienes intermedios & $\ldots$ & $\ldots$ & $\ldots$ & $33.5^{2}$ & $\cdots$ & $\cdots$ & $\cdots$ & $\cdots$ \\
\hline Bienes de capital & $\cdots$ & $\ldots$ & $\ldots$ & $10.6^{2}$ & $\ldots$ & $\ldots$ & $\ldots$ & $\ldots$ \\
\hline
\end{tabular}


Cuadro 7 (conchustion)

\begin{tabular}{|c|c|c|c|c|c|c|c|c|}
\hline Pais" & $1925 / 1927$ & $1932 / 1937$ & $1945 / 1950$ & $1960 / 1965$ & $1967 / 1970$ & $1972 / 1977$ & $1978 / 1981$ & $1982 / 1986$ \\
\hline \multicolumn{9}{|l|}{ Nicaragua } \\
\hline Promedio & $\ldots$ & $\cdots$ & $\cdots$ & $\cdots$ & $\cdots$ & $54.4^{w}$ & $\cdots$ & $\cdots$ \\
\hline Bienes de consumo & $\cdots$ & $\cdots$ & $\ldots$ & $59.6^{1}$ & $92.2^{\mathrm{D}}$ & $42.4^{w}$ & $\cdots$ & $\cdots$ \\
\hline Bienes intermedios & $\cdots$ & $\cdots$ & $\ldots$ & $33.0^{r}$ & $56.1^{\mathrm{u}}$ & $27.7^{w}$ & $\cdots$ & $\cdots$ \\
\hline Bienes de capital & $\cdots$ & $\cdots$ & $\ldots$ & $14.0^{1}$ & $12.6^{2}$ & $10.8^{w}$ & $\cdots$ & $\cdots$ \\
\hline \multicolumn{9}{|l|}{ Unuguay } \\
\hline Promedio & $\cdots$ & $\cdots$ & $\ldots$ & $\cdots$ & $\ldots$ & $139.0^{\mathrm{bbb}}$ & $\cdots$ & $\cdots$ \\
\hline Bienes de consumo & $\ldots$ & $\cdots$ & $\ldots$ & $\cdots$ & $\cdots$ & $133.0^{\mathrm{ltb}}$ & $\cdots$ & $0.0-15.0^{\mathrm{cc}}$ \\
\hline Bjenes de intermedios & $\ldots$ & $\ldots$ & $\ldots$ & $\cdots$ & $\cdots$ & $70.0^{\mathrm{bb}}$ & $\ldots$ & $0.0-15.0^{\mathrm{sc}}$ \\
\hline Bienes de capital & $\cdots$ & $\cdots$ & $\cdots$ & $\cdots$ & $\cdots$ & $\cdots$ & $\cdots$ & $0.0-15.0^{c 4}$ \\
\hline
\end{tabular}

Fuentes: Banco Mundial; BIRF; Naciones Unjdas; CLPAL; Fondo Monetario Internacional: Exchange Restrictions Annual Report (varios años); Cleplan; Universidad Católica de Chile: Cuadernos de Economia, Nos 54-55, Santiago de Chile, 1981 ; Sociedad de las Naciones: Tariff Level indices, Ginebra, 1927; Bela Belassa: Development strategies in semi-industrial economies, Baltimore, Maryland: The John Hopkins University Press, 1982; y Estructura de ba protection en palses en deserrollo, Centro de Estudios Monetarios Latinoamericanos, 1972; Carlos Diaz-Alejandro: Foreign Trade Regimes and Economic Development: Colombia, Nueva York: Columbia University Press, 1976; Manuel Martinez del Campo: Industrialización en México: hacia un análisis crttico, México, D.F.: El Colegio de México, 1985.

a Nivel arancelario (1925).

b 1927. Los bienes de consumo son manufacturas de algodón y lana; los bienes intermedjos son insumos agricolas, materias primas, aceites, etcétera.

Arancel ad valorem. No se incluyen derechos especificos.

d 1962 (valor máximo).

- 1969 (protección nominal).

r 1976. Bienes manufacturados.

s 1979. Protección nominal.

b 1986. Escala de tasis arancelarias.

i 1936 y 1951, respectivamente. (Incidencia media de los derechos aduaneros: derechos aduaneros divididos por el valor de las importaciones).

i 1966 y 1967, respectivamente (protección nominal).

k 1977 y 1980 , respectivamente (articulos manufacturados).

11986 (derechos de importación).

$m$ Antes de 1928 (arancel básico).

n 1932. Los bienes de consumo son artículos suntuarios.

- 1961 (protección nominal).

P 94.0 corresponde a 1973 y 24,0 corresponde a 1977.

4 1979-1982 y 1986, respectivamente.

r 1927, 1936, 1951 y 1959, respectivamente. Promedio de las tasas arancelarias nominales para todas las importaciones.

- 1975 y 1979 , respectivamente.

1959 (aranceles nacionales antes del Mercado Común). Atancel nominal medio para algunos grupos de productos manufacturados.

a 1967 (atanceles del Mercado Común). Aranceles nominales medios para algunos grupos de productos manufacturados. Las cifras utilizadas para Nicaragua se aplican a 1960 y 1968 , respectivamente.

$\checkmark \quad 1973$ y 1977 , respectivamente (tasa arancelaria nominal). La tasa arancelaria nominal es el arancel nominal dividido por las importaciones provenientes de fuera del Mercado Común Centroamericano (MCCA).

* 1972. Equivalentes ad valoren del arancel externo comán. Los bienes intermedios son productos alimenticios.

x 1981. Tasas arancelarias nominales.

y 1929, 1937 y 1948, respectivamente (coeficiente de derechos aduaneros). El coeficiente de derechos aduaneros es el cuociente a valores corrientes de los derechos aduaneros $y$ las importaciones totales.

* 1960. Protección arancelaria nominal.

*a $1970,1975,1979$ y 1982 , respectivamente. Nivel arancelario (promedio ponderado).

bb 1976 (arancel medio).

с $1985-1986$ (escala). 
desarrollados la prolongada y muy onerosa deflación de precios internos de acuerdo a la política del patrón oro. Sucedió así en parte por la magnitud relativa de los trastornos externos, pero sobre todo por decisiones conscientes de politica, puesto que, técnicamente hablando, todos los países podrían haber optado por la deflación.

La recuperación más oportuna y vigorosa de las economías latinoamericanas fue también fomentada por la aplicación de políticas monetarias de tinte más expansionista que deflacionario. A su vez, esta diferencia tuvo relación con el más oportuno abandono del llamado proceso de ajuste automático, y permitió el mantenimiento de tipos de interés interno reales mucho más bajos que los de países que persistieron durante más tiempo en la ruta deflacionaria, como los Estados Unidos. La oferta monetaria estadounidense se contrajo $16 \%$ entre $1925 / 1929$ y $1930 / 1934$; en cambio, la oferta monetaria de Brasil se elevó $18 \%$, la de México $13 \%$, la de Chile $11 \%$ y la del Uruguay alrededor de $6 \%$. A manera de contraste, casi la mitad de la oferta monetaria de Cuba se evaporo durante este período ${ }^{29}$.

Además, las posibilidades de recuperación en América Latina aumentaron considerablemente gracias a la amplia moratoria concedida a los pagos de la deuda externa en los primeros años del decenio de 1930. En efecto, únicamente Argentina y República Dominicana mantuvieron el servicio de su deuda durante este período. Finalmente, y también en agudo contraste con la situación de los años ochenta, los países latinoamericanos no tuvieron que enfrentar una fuga de capitales ${ }^{30}$.

\section{Visión general de la recuperación y el crecimiento}

En América Latina, como en el mundo en general, la Depresión tocó fondo en 1932. Sin embargo, en sólo dos años el producto regional no sólo se habfa recuperado sino que había sobrepasado el nivel de 1929, y en 1937 superaba en $20 \%$ el punto culminante previo a la crisis. A modo de contraste, el índice del producto interno bruto del conjunto de los países industriales no recupe-

\footnotetext{
${ }^{29}$ Carlos Díaz-Alejandro, op. cit., 1982, cuadro 20.7.

${ }^{30}$ Para un análisis histórico comparativo de ambos temas, véase Félix, op. cil., 1987.
}

ró su nivel de 1929 sino hasta 1936 , y en 1937 sólo superaba en $7 \%$ el punto máximo anterior a la Depresión. Los resultados de América Latina son más notables aún por cuanto la actividad económica del principal país con el que mantenía relaciones comerciales aún se mantenía en 1937 por debajo del nivel de 1929. En efecto, en los Estados Unidos la recuperación no se completó hasta 1939 , año en que se aceleró en gran medida el proceso de rearme ${ }^{31}$.

Además, en 1937 el producto regional de Asia excedía en $10 \%$ el de 1929 , pero sólo supe. raba en $6 \%$ su nivel de 1932; el producto interno bruto de América Latina, en cambio, se expandió más de $39 \%$ entre 1932 y 1937 . Por otra parte, cuando América Latina sobrepaso su producto interno bruto anterior a la Gran Depresión en 1934, lo hizo con un volumen de importaciones que superaba apenas la mitad de su nivel de 1929; ese mismo año, el producto de Asia era casi el mismo de 1929 , pero su volumen de importaciones sólo se había reducido $13 \%$ respecto del de este último año ${ }^{32}$.

Entre 1939 y 1945 las economías latinoamericanas continuaron alcanzando tasas de crecimiento superiores a las de gran parte del resto del mundo, a pesar de los trastornos causados por la Segunda Guerra Mundial y la brusca contracción de la economía de los Estados Unidos entre 1944 y 1948. Por otra parte, la sostenida expansión latinoamericana fue promovida por el marcado crecimiento de la economía de los Estados Unidos entre 1939 y 1944, y desde 1946 en adelante por una fuerte recuperación de la relación de precios del intercambio de la región. Así, entre 1939 y 1945 el producto interno bruto regional creció $3.4 \%$ por año y entre 1945 y 1950 aumento anualmente $5.3 \%$ (cuadro 1). Estas cifras se comparan con una tasa de crecimiento de alrededor de $2.5 \%$ entre 1929 y 1939 .

Para el conjunto del período 1929-1950, la tasa de crecimiento anual del producto regional fue $4,4 \%$ (cuadro 8 ). En contraste, la economía estadounidense se expandiố a un ritmo de $2.7 \%$ anual durante el mismo lapso ${ }^{39}$.

\footnotetext{
${ }^{31}$ B. Eichengreen y R. Portes, op. cit., 1987, cuadros 3 y 4, y A. Maddison, op. cit., 1982, cuadro A7.

${ }^{32} B$. Eichengreen y R. Portes, op. cil., cuadro 4.

${ }^{33}$ Maddison, op. cit., 1982, cuadro 7A.
} 
Cuadro 8

AMERICA LATINA: EVOLUCION DEL PRODUCTO INTERNO BRUTO ÉN ALGUNOS PAISES, 1929-1950" (Tasas de crecimiento medio anual)

\begin{tabular}{|c|c|c|c|c|c|c|c|c|c|c|}
\hline \multirow{2}{*}{ Pats } & \multirow{2}{*}{ Total } & \multirow{2}{*}{$\begin{array}{c}\text { Por } \\
\text { habitante }\end{array}$} & \multicolumn{4}{|c|}{ Bienes conerciables } & \multicolumn{3}{|c|}{ Bienes no comerciables } & \multirow[b]{2}{*}{$\begin{array}{l}\text { Servicios } \\
\text { no básicos }\end{array}$} \\
\hline & & & Total & Agricultura & Mineria & $\begin{array}{c}\text { Industria } \\
\text { manufacturera }\end{array}$ & Total & Construcción & $\begin{array}{c}\text { Servicios } \\
\text { básicos }\end{array}$ & \\
\hline Argentina & 2.3 & & 2.1 & 0.9 & 5.6 & 8.2 & 2.7 & 2.5 & 3.4 & 2.6 \\
\hline Brasil & 3.6 & & 4.0 & 2.1 & 3.2 & 6.4 & 3.3 & $\cdots$ & $\cdots$ & $\ldots$ \\
\hline Colombia & 3.6 & & 3.3 & 2.3 & 2.8 & 8.0 & $\cdots$ & 3.0 & $\ldots$ & $\ldots$ \\
\hline Chile $^{e}$ & 3.4 & & 2.7 & 1.9 & -1.0 & 6.1 & 3.7 & 3.8 & 2.7 & 3.8 \\
\hline Ecuador ${ }^{c}$ & 6.5 & & 7.3 & 8.1 & 1.7 & 6.0 & 5.6 & 7.8 & 11.3 & 4.8 \\
\hline Honduras & 1.4 & & 0.9 & 0.3 & 3.0 & 4.0 & 2.9 & 4.0 & 3.1 & 2.6 \\
\hline México & 4.2 & & 4.3 & 3.9 & 0.7 & 6.1 & 4.4 & $\mathbf{f}$ & 5.1 & 4.0 \\
\hline Paraguayg & 2.4 & & 2.3 & 2.2 & $\ldots$ & 2.3 & 2.3 & 5.9 & 3.6 & 2.1 \\
\hline Perúh & 4.5 & & 4.1 & 3.9 & 2.1 & 5.7 & 4.9 & 8.6 & $\mathrm{fI}$ & 4.5 \\
\hline Uraguay $^{i}$ & 2.8 & & 2.7 & 2.2 & $\ldots$ & 3.0 & 2.9 & 8.1 & 2.5 & 2.6 \\
\hline Venezuela & 7.1 & & 5.9 & -0.3 & 9.4 & 7.5 & 6.9 & 12.8 & $\ldots$ & $\ldots$ \\
\hline
\end{tabular}

Fuente: CEPAL, a base de datos oficiales.

A menos que se indique lo contrario.

- Precios de 1970.

c 1939-1950.

d 1946-1950.

c 1940-1950.

f Incluidos en otros servicios.

8 1938-1950.

b 1945-1950.

i 1935-1950.

j 1936-1950. 
Finalmente, cabe observar que la participación de América Latina en las exportaciones mundiales disminuyó de $8.9 \%$ en 1929 a $7.9 \%$ en 1938 (que fue la misma cifra registrada en 1913); sin embargo, en 1947 había aumentado a $12.2 \%$, antes de caer a $11.4 \%$ en 1950 . Por otra parte, su participación en las importaciones mundiales disminuyó de $6.8 \%$ en 1929 a $6.3 \%$ en 1938 , culminó con $11.3 \%$ en 1947 , y descendió bruscamente a $8.6 \%$ en $1950^{34}$, a pesar de una recuperación de más de $20 \%$ en su relación de precios del intercambio entre 1947 y 1950 . En efecto, en 1950 la relación de precios del intercambio de la región llegó a su nivel más alto desde 1929 (es decir, 93.6 respecto de 100 ), cifra que, para la región en su totalidad, no se ha alcanzado de nuevo (cuadro 2). Evidentemente, en los últimos años del decenio de 1940 ya estaban tomando forma las politicas que habrían de ejercer decisiva influencia en el desempeño económico de América Latina desde la posguerra hasta 1973 y aún después.

A continuación se consideran brevemente algunas de las ideas básicas de un latinoamericano, cuyos planteamientos económicos se forjaron directamente en la experiencia de la Gran Depresión, pero alcanzaron máxima influencia en los años cincuenta y sesenta.

\section{III}

\section{La tesis de Prebisch}

Al publicar su innovador y controvertido estudio del desarrollo económico de America Latina en $1949^{35}$, Raúl Prebisch tenía dos objetivos, y entre ellos probablemente no incluía el que efectivamente consiguió: fundar una escuela latinoamericana de pensamiento económico. Intentaba exponer las causas del atraso económico de la región en relación con los países industrializados, y hacer que sus habitantes aceptaran los argumentos en favor de la intervención del libre juego de las fuerzas de mercado, casi como la preparación de un programa de políticas para transformar las economias latinoamericanas. El alcance de su aporte no puede ser debidamente valorado en los marcos del presente texto. En él sólo se intenta analizar brevemente la proposición que más se ha identificado con la figura de Prebisch, y que lo ha transformado en blanco de mayores ataques; con ello se procura sugerir la necesidad de reevaluar su tesis básica y de volver a presentar las ideas que habrían de tener tan notable influencia sobre las políticas económicas de América Latina

\footnotetext{
${ }^{34}$ Union Panamericana, The Foreign Trade of Latin America since 1913, Washington, D.C., 1952, p. 3.

${ }^{35}$ Raúl Prebisch, Desarrollo económico de Americo Latiza y ses principales problemas (E/CN.12/89), Santiago de Chile, CEPAL, 1949.
}

y de otros países en desarrollo durante la posguerra ${ }^{36}$.

A lo largo de los años, Prebisch utilizó argumentaciones diversas para explicar su muy criticada conclusión de 1949 , respecto de un deterio* ro secular de la relación de precios del intercambio de las economias latinoamericanas desde mediados del decenio de 1860 hasta mediados del decenio de $1930^{37}$. Sin embargo, la explicación originalmente contenida en su estudio de 1949 no sólo soportó mejor el paso del tiempo, sino que se convirtió ulteriormente en la proposición

\footnotetext{
${ }^{36}$ En su análisis original del desarrollo económico de América Latina, en otros estudios que escribio a principios del decenio de 1950, Prebisch hizo varios aportes generalmente desestimados, que fueron precursores de lo que mucho más tarde llego a conocerse como macroeconomfa de economia abierta. Hubo economistas estadounidenses que inadvertidamente redescubrieron su primer análisis (aunque ampliándolo, en gran medida), y finalmente se vieron forzados a abandonar la ficción de que los Estados Unidos continuaban siendo una economia cerrada. Como se examina más adelanıe, su estudio de 1949 fue también precursor de lo que más tarde se convirtió en el principio central de las publicaciones especializadas sobre captación de rentas.

${ }^{3}$ Un año después que Prebisch, H.W. Singer tambien publico una conclusión similar en "The distribution of gains between investing and borrowing countries", American Economic Review, vol. 40, $\mathrm{N}^{\circ} 2$ (mayo de 1950).
} 
central en torno a la cual giran las publicaciones sobre captación de rentas. Paradójicamente, sin embargo, hasta el día de hoy persiste una áspera controversia sobre si la relación de precios del intercambio de los productores primarios presentó alguna vez, o sigue presentando, un deterioro secular ${ }^{88}$.

En sintesis, Prebisch originalmente explico su tesis respecto de un evidente deterioro secular de la relación de precios del intercambio de las economías latinoamericanas argumentando que en el centro de la economía mundial (denominación que daba a los países industrialmente más adelantados) las coaliciones de trabajadores y de productores van aumentando gradualmente los precios internos de los artículos producidos en industrias altamente concentradas; por ello, los precios internacionales de estos productos (según un supuesto realista de país grande), se ubican por encima de los niveles de equilibrio del mercado en el curso de sucesivos ciclos económicos. Logran este resultado resistiéndose a las reducciones de precios y salarios necesarios, durante las depresiones ciclicas, para mantener el pleno empleo en el sector manufacturero (aunque no necesariamente en la economía en general), y quizás también obteniendo durante las recuperaciones cíclicas aumentos de precios superiores a los competitivos ${ }^{39}$.

En cambio, en la periferia de la economía mundial (término con que se designan los países en desarrollo), los precios de los productos primarios (y de los factores) caen al mismo ritmo de los descensos cíclicos en el centro, y aumentan en consonancia con el alza de su demanda durante las reactivaciones cíclicas en este último.

Según Prebisch, el mantenimiento de los precios internacionales de los productos prima-

\footnotetext{
${ }^{38}$ Véase, por ejemplo, el debate reciente entre H.W. Singer y B. Balassa sobre esta cuestion: H.W. Singer "The terms of trade controversy and the evolution of soft fimancing: early years in the U.N.", 275-303, y B. Balassa "Comentario", Pioneros del desarrollo, G.M. Mejer y D. Seers (comps.), Madrid, Editorial Tecnos, 1986 (publicación del Banco Mundial).

${ }^{39} \mathrm{Un}$ análisis histórico detallado del alcance de las coaliciones macroeconómicas en los países desartollados, y de sus efectos distorsionadores sobre los precios, se presenta en $M$. Olson, The Rise and Decine of Nations: Economic Growth, Stagflation and Sacial Rigidities. New Haven, Connecticut, Yale University Press, 1982.
}

rios a niveles de equilibrio del mercado durante sucesivos ciclos económicos, refleja una histórica falta de coaliciones eficaces entre productores $y$ trabajadores de la producción de bienes primarios a nivel mundial. A su vez, esta falta fundamentalmente proviene de la abundancia de la mayoría de los recursos naturales en el mundo $y$, en los últimos ańos, de la aparición gradual de un excedente estructural de mano de obra en la periferia. Mientras la abundancia de recursos naturales en el conjunto de la economía mundial impide mantener a largo plazo grados significativos de concentración en la producción de la mayoría de los bienes primarios en la economía internacional en general (conforme a una suposición realista de país pequeño) y por lo tanto, impide asimismo el establecimiento de precios internacionales superiores a los del mercado para estos productos en el largo plazo, el excedente estructural de mano de obra perjudica la posibilidad de mantener salarios superiores a los del mercado en la producción de bienes primarios ${ }^{40}$.

Si los precios internacionales de artículos manufacturados producidos en industrias concentradas aumentan así gradualmente por sobre los niveles competitivos en sucesivos ciclos económi$\cos , y$ los precios internacionales de los productos básicos se mantienen en el transcurso del tiempo a niveles competitivos, la relación de precios del intercambio de los países periféricos se deterioraría permanentemente en tanto estos países siguieran concentrando su producción en bienes comerciables que les otorgan extraordinarias ventajas comparativas ${ }^{41}$. El análisis de Prebisch,

\footnotetext{
${ }^{40}$ Las coaliciones laborales podrian impulsar los salarios por sobre el costo de oportunidad social de la mano de obra dentro de los distintos palses si hubiera, a nivel nacional, una concentración de los derechos de propiedad sobre los recursos naturales. Sin embargo, los precios de producción del producto respectivo todavia estarían determinados competitivamente por la competencia en el mercado internacional. En efecto, como sugiere la evolución reciente del precio internacional del petróleo, la fijación de los precios internacionales por encima de los niveles competitivos mediante un acuerdo de los productores, es al parecer insostenible en el largo plazo, incluso si se trata de un producto básico, cuya demanda mundial es sumamente inelástica.

"'Contra lo que erróneamente afirman algunos de sus críticos, ni este aryumento básico ni los datos que parecian mostrar un deterioro secular de la relación de precios del intercambio de los paises latinoamericanos desde mediados del decenio de 1860 hasta mediados del decenio de 1930 ,
} 
tal como él lo señaló repetidamente en sus obras publicadas y sus declaraciones públicas, explica también la protección cada vez mayor de los productores primarios en los paises del centro. Se ha documentado el aumento, más o menos progresivo en el tiempo, de los subsidios a los productos básicos en los países industrializados ${ }^{42}$. La tendencia ha perjudicado además progresivamente los precios internacionales de un creciente número de materias primas producidas tanto en el centro como en la periferia: la disminución de los precios internacionales de estos bienes lleva a otorgar cada vez más subsidios a sus productores en los países industrializados, lo que a su vez genera exceso de oferta, nuevas disminuciones de los precios internacionales y otras rondas de subsidios.

Si la relación de precios del intercambio para los productos primarios en realidad no hubiera disminuido en el transcurso del tiempo, podría ser difícil explicar el notorio y progresivo aumento de la protección a productores primarios en los países industrializados. Sin embargo, los intereses agrícolas han podido organizarse y ejercer su influencia en la mayoría de los pafses desarrollados, a pesar de la considerable - pero decreciente- dispersión de los productores. Tal vez por este medio han logrado obtener para sus productos precios internos más que competitivos (es decir, superiores a los internacionales), aun cuando no se haya deteriorado la relación internacional secular de precios del intercambio ${ }^{43}$.

dieron pie a Prebisch para sostener que la relación de precios del intercambio de los paises periféricos se deterioraría permanentemente en el transcurso del tiempo. Una tendencia en contrario podía surgir de la competencia entre paises industrializados. Otra podía surgir de su propio análisis normativo, que de hecho instaba a la periferia a industrializarse precisamente para poder frenar el deterioro secular de su relación de precios del intercambio.

${ }^{42}$ Véase, por ejemplo, A.M. Baliscan y.J.A. Roumasset, "Public choice of economic policy: the growth of agticulture protection", Review of World Economics, 1987, pp. 282-249, y B. Heitger, "Import protection and export performance. Their impact on economic growth", Review of World Economics, 1987, pp. 249-261.

${ }^{49}$ Cabe observar que el eficaz funcionamiento de coaliciones de productores agricolas en el plano nacional no invalida nuestra afirmación de que, a escala mundial, la abundancia y dispersión de los productores impide mantener incluso formar-coaliciones internacionales eficaces de productores de bienes básicos.
Quizás lo que ha ocurrido es que, durante sucesivas contracciones cíclicas de la actividad económica, estos grupos de intereses han obtenido subsidios compensatorios, y luego han logrado mantenerlos, al menos parcialmente, durante sucesivas recuperaciones cíclicas. De ser así las cosas, sin embargo, el exceso de oferta resultante, junto con las consiguientes barreras a las importaciones provenientes de competidores en la periferia, conduciria necesariamente a una disminucion secular gradual de los precios internacionales de estos productos primarios.

Hemos trazado así un periplo que nos conduce de nuevo al argumento de Prebisch. En efecto, incluso si una disminución secular de la relación de precios del intercambio de productos primarios no provocara en los paises industrializados la expansión progresiva de la protección de los productores primarios, el crecimiento progresivo de los subsidios, debido a las presiones de los intereses agrícolas organizados, efectivamente podría generar un deterioro secular de los precios internacionales de sus productos en relación a los niveles que hubiera establecido la competencia en una situación no protegida. Si es así, el lúcido y creador anátisis de Prebisch respecto de los efectos de las coaliciones de productores en los sectores manufactureros del centro se aplica igualmente a los efectos de las coaliciones agricolas en el centro, con una diferencia: las primeras aumentan tanto los precios internos como los internacionales de los productos manufacturados por encima de los niveles competitivos; las segundas inflan los precios internos de los productos básicos en el centro por encima de los precios internacionales competitivos, pero hacen descender los respectivos precios internacionales, ubicándolos bajo sus niveles de competitividad. Esta es evidentemente la razón por la que Prebisch se abstuvo de agrupar a los productores primarios del centro con los productores primarios de la periferia ${ }^{44}$.

\footnotetext{
${ }^{44}$ Por cierto, cuando un pais antes periférico se incorpora a la categoría de los paises industrializados, cabe prever que a la larga otorgará subsidios a sus propios productores primarios. A este respecto puede recordarse, por cierto, el caso de Japón, y más recientemente de Corea. Véase por ejemplo, M.V. Martin y J.A. McDonald, "Food grain policy in the Republic of Korea: the economic cost of self-sufficiency", Economic Development and Cullural Change, vol. $34, \mathrm{~N}^{\circ} 2$, enero de 1986, pp. 315-331.
} 
Al seguir el original análisis de Prebisch, hemos podido remontarnos a la génesis de las distorsiones de los precios internacionales, y sugerir que puede atribuírseles directamente una parte considerable, $y$ tal vez la principal, de las distorsiones de los precios de producción interna que se registraron en America Latina desde mediados del decenio de 1930 hasta mediados del decenio de 1950, cuando las políticas macroeconómicas y comerciales internas aumentaron considerablemente la frecuencia de las distorsiones de precios de la producción en las economías de la región. El análisis de Prebisch nuevamente se torna especialmente pertinente en los años ochenta, tema que se abordará en una próxima oportunidad.

A diferencia de las distorsiones de precios de la producción interna provocadas por la aplicación de políticas, cuyos efectos se limitan esencialmente a transferencias internas de ingresos (sin considerar los efectos de las actividades de captación de rentas), las distorsiones de precios internacionales, a que ya se ha hecho referencia, perjudican en forma directa y proporcional los ingresos de la periferia. Además, esta pérdida de ingresos puede incidir en el producto, dado que esos precios de equilibrio no determinados en el mercado impedirían el mantenimiento del pleno empleo, a menos que los precios nominales de los bienes y servicios no comerciados fueran suficientemente flexibles a la baja. Otra posibilidad es la inflación, si el ajuste debe realizarse elevando el tipo de cambio nominal para hacer frente a las influencias de los grupos de intereses. Estas distorsiones de precios internacionales acarrean asimismo transferencias internas de ingresos en el centro, pero se traducen alli en una ganancia de ingresos proporcional ́a expensas de la periferia), to cual explica por qué los precios de equilibrio no determinados en el mercado no pueden generar allí un desempleo significativo, aunque sí puedan causar inflación. Una vez que se manifiestan las ramificaciones dinámicas de la distorsión de precios, la capacidad de reacción de la economía del centro, en términos de producto y empleo, gradualmente se va restringiendo. Desde luego, las distorsiones endógenas inducidas por las políticas pueden empeorar los resultados económicos en la periferia.

El estudio de Prebisch en 1949 sobre el desarrollo económico de América Latina, así entendi- do, presenta un análisis innovador de las consecuencias de la interacción de un sector de precios rígidos con un sector de precios flexibles, en una economía mundial unificada. Además, y a diferencia del de Keynes, por ejemplo, su análisis está firmemente asentado en una explicación microeconómica de los orígenes de las distorsiones del mercado de productos y de factores.

Las similitudes entre el paradigma de Prebisch, publicado en 1949, y la célebre teoría de Olson respecto de la grandeza y decadencia de las naciones, publicada 33 años más tarde, son impresionantes ${ }^{45}$. Una de las diferencias principales consiste en que Prebisch centró su atención en la interacción de un centro con precios no flexibles a la baja y una periferia de precios flexibles, mientras que Olson consideró en su estudio sectores de precios flexibles e inflexibles dentro de las distintas economías. Y si bien Olson desarrolló un tratamiento mucho más riguroso $y$ amplio de los fundamentos microeconómicos de las coaliciones macroeconómicas, el análisis de Prebisch, de tinte decididamente afin a la macroeconomia de economía abierta, se adelantaba muchísimo a su tiempo.

¿Pero acaso tenta Prebisch la razón? Si hubiera que juzgar su proposición sobre la base de la argumentación en que se basaron las recompensas otorgadas por el comité encargado de discernir el Premio Nobel por pensamiento económico creador, la respuesta sería sí, ya que en $1985 \mathrm{~J}$. Buchanan obtuvo el Premio Nobel de Economía por sus originales aportes a las publicaciones sobre decisiones públicas en el marco de la captación de rentas. Estos aportes al igual que otros publicados sobre ese tema, no parecen en absoluto innovadores cuando se ha leído a Prebisch ${ }^{46}$.

\footnotetext{
${ }^{45} \mathrm{M}$. Olson, op. cti., 1982.

${ }^{46}$ Consideremos, por ejemplo lo siguiente:

"Cabe aclarar nuestra afirmación de que los mercados en desequilibrio por exceso de oferta implican desempleo de recursos. En un análisis del equilibrio general, la suposición normal es que el grupo excluido abandonará la actividad y emprenderá otras nuevas. Las barreras al ingreso asignan inadecuadamente los tecursos, pero no crean desempleo. En nuestro equilibrio basado en coaliciones, los individuos siguen involuntariamente desempleados, por cuanto estarian dispuestos a aceptar un trabajo al mismo salario que están recibjendo actualmente algunas otras personas con su misma dotación de capital humano, e incluso a la productividad ingreso marginal que tendrian en una economía libre de
} 
Por otra parte, al leer los artículos en contra y a favor de la tesis de Prebisch, se aprecia un rechazo mayoritario de los datos sobre los que basa su conclusión respecto de un deterioro secular de la relación de precios del intercambio de América Latina desde el decenio de 1860 hasta el decenio de $1930^{47}$.

En vez de empantanarnos en ese debate, consideraremos cómo aparece la evolución de la relación de precios del intercambio de América

coaliciones, pero a veces no pueden obtener semejante empleo o trabajo por mucho que busquen. Como explica Olson (1982), los países en que sólo un pequeño segmento de la economía ha sido subyugado por grupos de intereses normalmente no tienen un desempleo significativo, porque el sector de precios flexibles, que es mucho más grande, absorbe a los desempleados sin una gran reducción de los salarios y los precios de ese sector. En cambio, si gran parte de la economía de un pais está controlada por coaliciones de distribución, en los sectores controlados la exclusión impedirá que una parte importante de la oferta de factores en el conjunto de la economía se emplee en los sectores que le habrian cotrespondido en otras circunstancias. El desplazamiento de recursos al sector de precios flexibles será entonces can grande que surgirán grandes variaciones en las rentas de factores homogéneos. Serán tantas las personas en el sector de "venta de manxanas en las esquinas" que el empleo en este sector podrá llegar a considerarse, en las depresiones económicas, como sinónimo de desempleo involuntario. En un extremo, el salatio en el sector de precios flexibles puede llegar a niveles inferiores a los salarios de subsistencia de trabajadores retativamente laboriosos, $e$ incluso a cero.

"Mientras más extendidos estén los grupos de intereses, aś como los precios no basados en el mercado sino en las presiones de grupos y en cartelizaciones, mayores serán las disparidades en las rentas de recutsos humanos homogéneos. Mientras mayores sean estas disparidades, más conviene dedicarse, buscar y esperar puestos vinculados a los grupos que los distribuyen. En ese caso, la búsqueda extra no es, como en una economia puramente competitiva, una inversión socialmente eficiente en información; se trata de una búsqueda de rentas que de lo contrario percibirían otras personas. El tiempo que se dedique a buscar y esperar ocupaciones es un tipo de gasto social o desempleo involuntario que surge de las coaliciones de distribución que crearon las disparidades entre las rentas". (D.C. Colander y M. Olson, "Coalitions and macroeconomics", Neoclassical Political Economy. The Analysis of Rent-Seeking and Dup Actrvities, David C. Colander (comp.), Cambridge, Massachusetts, Ballinger Publishing Company, 1984, pp. 120-121).

${ }^{47}$ Dos de las objeciones principales consisten en que Prebisch calculo indirectamente la relación de precios del intercambio de América Latina sobre la base de la del Reino Unido (es decir, como la reciproca de la relación de precios del intercambio del Reino Unido) y que no tomó en cuenta el efecto de lá disminución de tos costos internacionales del transporte que tuvo lugar durante este período.
Latina entre la Gran Depresión y la crisis actual. Entre 1928 y 1987 la tasa tendencial del cambio del índice de precios de las exportaciones de mercancías de América Latina fue $-0.3 \%$ anual, mientras que la tasa tendencial del cambio del valor unitario de sus importaciones de mercanças fue de $0.25 \%$ anual. Su relación bruta de intercambio de trueque se deterioró a la tasa de $0.55 \%$ anual durante este período (cuadro 2).

¿Son acaso seis decenios tiempo suficiente para hablar de un deterioro secular de la relación de precios del intercambio de las economías latinoamericanas? De no ser asi, ¿cómo se explica que, a partir de los primeros años del decenio de 1980, autoridades como el Fondo Monetario Internacional promovieran ajustes masivos en paises en desarrollo, en parte sobre la base de sostener de que el deterioro de la relación de precios del intercambio experimentada desde mediados del decenio de 1970 tenía el carácter de una circunstancia permanente? ${ }^{48}$.

Volviendo a los datos de largo plazo sobre la relación de precios del intercambio de América Latina, cabe señalar también que el deterioro observado habría sido incluso mayor si la región no hubiese acogido la proposición normativa que se desprendió del análisis positivo hecho por Prebisch; es decir, si no hubiera fomentado la industrialización mediante una intervención en el libre juego de las fuerzas de mercado. Esto nos lleva a nuestro comentario final, y más importante, sobre la tesis de Prebisch.

En efecto, si bien consideramos que el análisis positivo de Prebisch fue acertado, el atractivo de su enfoque, junto a una preocupación casi exclusiva por la periferia como un todo $\rightarrow$ no con el aspecto de país pequeño que presenta el problema-llevó a múltiples y pronunciados excesos de política en América Latina en los años de posguerra. Para hacerle justicia, sin embargo, cabe señalar que él mismo fue uno de los primeros y más seyeros críticos de ciertas políticas que, paradójicamente, se basaban, aunque muy tenuemente, en su propio análisis.

(Traducido del inglés)

${ }^{18}$ Véanse, por ejemplo, "Conversación con el señor de Larosiere", Finanzas y Desarrollo, vol. 19, No 2 (junio de 1982), pp. 4-7, y M. Khan y M. Knight, "Determinants of current account balance of non-oil developing countries in the 1970s: an empirical analysis", IMF Staff $P$ apers, vol. $30, \mathrm{~N}^{\circ} 2$, diciem. bre de 1983, pp. 819-842. 